\title{
Dynamic installation and monotonic pullout of a torpedo anchor in calcareous silt
}

\author{
M. S. HOSSAIN*, C. D. O’LOUGHLIN* and Y. KIM*
}

\begin{abstract}
Challenges associated with dynamically installed anchors include prediction of the anchor embedment depth, which dictates the anchor's holding capacity. This is particularly true for calcareous sediments, as very little performance data exist for this anchor type in these soils. This paper reports results from a series of model tests undertaken to provide insight into the behaviour of a torpedo anchor during dynamic installation and monotonic pullout in lightly overconsolidated calcareous silt. The tests were carried out in a beam centrifuge, varying the drop height and consequently the impact velocity, and the consolidation period prior to anchor pullout. The mudline load inclination was also varied to encompass various mooring configurations. The centrifuge model test data were used to calibrate: $(a)$ an analytical dynamic embedment model, based on conventional bearing and frictional resistance factors but with strain-rate-dependent undrained shear strength for the soil; and $(b)$ an analytical quasi-static vertical pullout capacity model, accounting for reverse end bearing and frictional resistance. A total energy based expression, appropriate for calcareous silts, was proposed for predicting anchor embedment depth for a given anchor geometry, mass and impact velocity. For assessing anchor vertical holding capacity, a piezocone based direct design approach was also proposed, deriving anchor end bearing and frictional resistance from cone tip resistance and sleeve friction, respectively. Anchor capacity under inclined loading was presented as failure envelopes expressed in terms of dimensionless vertical and horizontal components of anchor net resistance, which agreed well with a finite-element based envelope developed for embedded foundations. The regain of anchor capacity was found to be in good agreement with predictions based on the cavity expansion framework.
\end{abstract}

KEYWORDS: anchors; calcareous soils; centrifuge modelling; failure; offshore engineering; silts

\section{INTRODUCTION}

Dynamically installed anchors are the most recent generation of anchoring systems for mooring floating facilities in deep waters. They have been identified as one of the most costeffective and promising concepts for future oil and gas development in emerging frontiers. The anchor is released from a design height above the seabed. This allows the anchor to gain velocity as it falls freely through the water column before impacting and embedding within the sediments.

The most commonly used dynamically installed anchors are rocket shaped, referred to as torpedo anchors, typically $12 \sim 17 \mathrm{~m}$ long and $0.8 \sim 1.2 \mathrm{~m}$ in diameter, with a dry weight of $230 \sim 1150 \mathrm{kN}$; they may feature up to four fins at the trailing edge (Fig. 1; Brandão et al., 2006). They are released from a height of $50 \sim 100 \mathrm{~m}$ above the seabed, achieving velocities up to $35 \mathrm{~m} / \mathrm{s}$. As of 2009 , more than 1000 torpedo anchors have been used for anchoring deepwater flowlines and floating facilities at the Campos Basin, offshore Brazil in water depths up to $1400 \mathrm{~m}$ (de Araujo et al., 2004; Brandão et al., 2006; Wilde, 2009), achieving anchor tip embedment depths in the range 1.5 2.4 times the anchor length. A similar anchor concept was trialled at the Gjøa field in the North Sea, off the western coast of Norway, where tip embedment depths were in the range 1.9 2.4 times the anchor length (Lieng et al., 2010). Another dynamically installed anchor design, referred to as

Manuscript received 4 September 2013; revised manuscript accepted 12 December 2014. Published online ahead of print 5 February 2015. Discussion on this paper closes on 1 July 2015, for further details see p. ii.

$*$ Centre for Offshore Foundation Systems (COFS), The University of Western Australia, Crawley, Western Australia. the OMNI-Max anchor, has been used in the Gulf of Mexico. Zimmerman et al. (2009) reported that 54 OMNIMax anchors were installed for temporary moorings in the Gulf of Mexico, achieving tip embedment of 1.17 2.2 times the anchor length. The seabed sediments in the Campos Basin, Gjøa field and Gulf of Mexico consist of clayey deposits with undrained shear strength of $2 \sim 7 \mathrm{kPa}$ at the mudline, increasing somewhat linearly with depth with a gradient of $1 \sim 3 \mathrm{kPa} / \mathrm{m}$.

Reliable anchor capacity data from field trials are rarely reported (Medeiros, 2002). The majority of the capacity data are from centrifuge model tests, which indicate that, for clay, (a) the vertical monotonic capacity is in the range 1.7 4.4 times the dry weight of the anchor, increasing with reconsolidation time, and $(b)$ the capacity increases as the mudline loading angle reduces (O'Loughlin et al., 2004; Richardson et al., 2009; Hossain et al., 2014).

However, few performance data exist for these anchor types in calcareous soils (Hossain et al., 2014), which are prevalent in many seabed deposits, particularly in the oiland gas-producing offshore regions of Australia. This paper addresses this gap by reporting centrifuge model test data on a torpedo anchor in lightly overconsolidated silt, addressing the effects of impact velocity, reconsolidation time and mudline loading angle on anchor performance. The data are used to examine the merit of design tools for predicting anchor embedment and capacity.

\section{CENTRIFUGE MODELLING}

Experimental programme

The experimental programme comprised centrifuge modelling of dynamic installation and monotonic pullout of a 


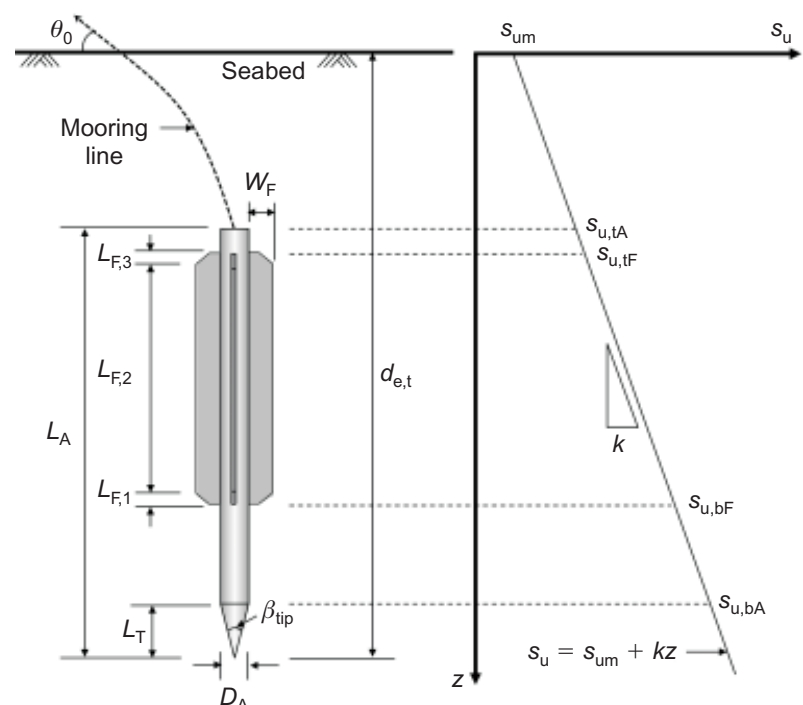

(a)

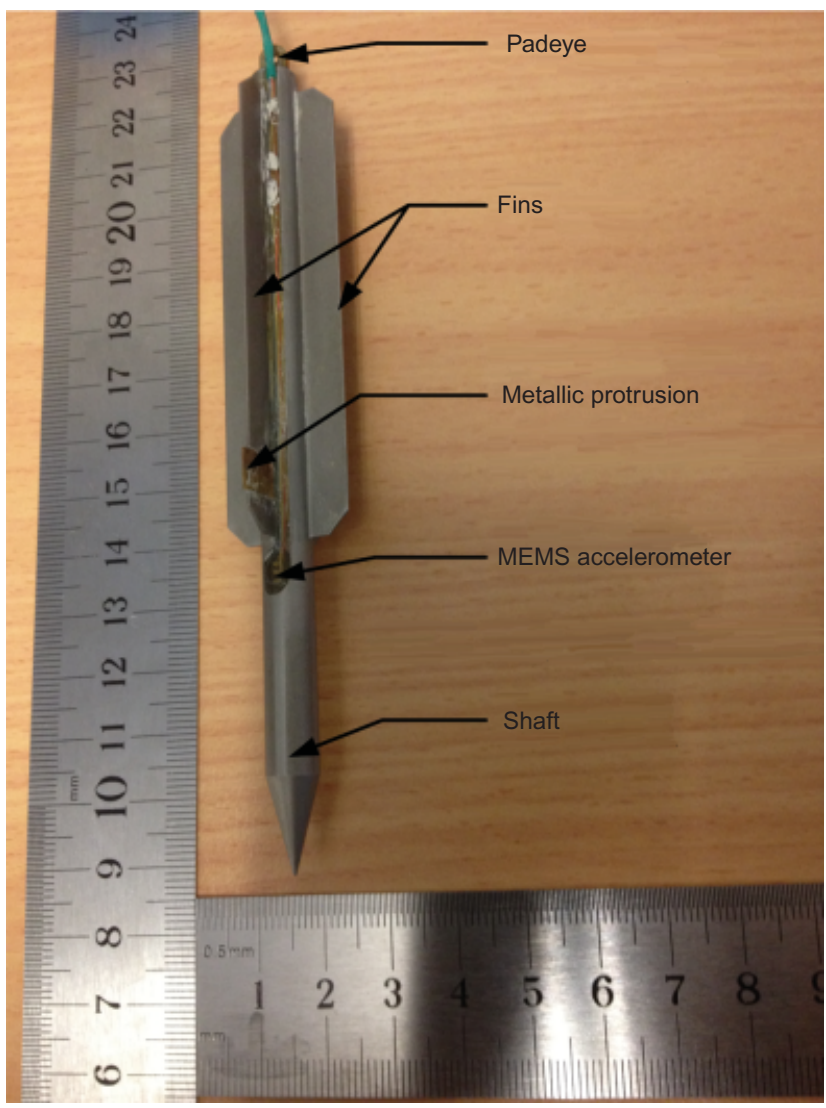

(b)

Fig. 1. Torpedo anchor: (a) schematic representation of installed torpedo anchor and idealised seabed strength profile; (b) centrifuge model anchor

torpedo anchor in calcareous silt. The work was carried out at $133.3 \mathrm{~g}$ in the beam centrifuge at the University of Western Australia (see Fig. 2; Randolph et al., 1991). It has a swinging platform radius of $1.8 \mathrm{~m}$ with a nominal working radius of $1.55 \mathrm{~m}$. The platform supports a standard rectangular 'strongbox', which has internal dimensions of 650 (length) $\times 390$ (width) $\times 325$ (depth) $\mathrm{mm}$, representing a prototype test bed of up to $87 \mathrm{~m}$ long by $52 \mathrm{~m}$ wide by $43 \mathrm{~m}$ deep at $133 \cdot 3 \mathrm{~g}$. In this study, the soil samples were confined within three narrower sample boxes (with internal dimensions of $598 \times 117 \times 300 \mathrm{~mm}$ ), with the boxes

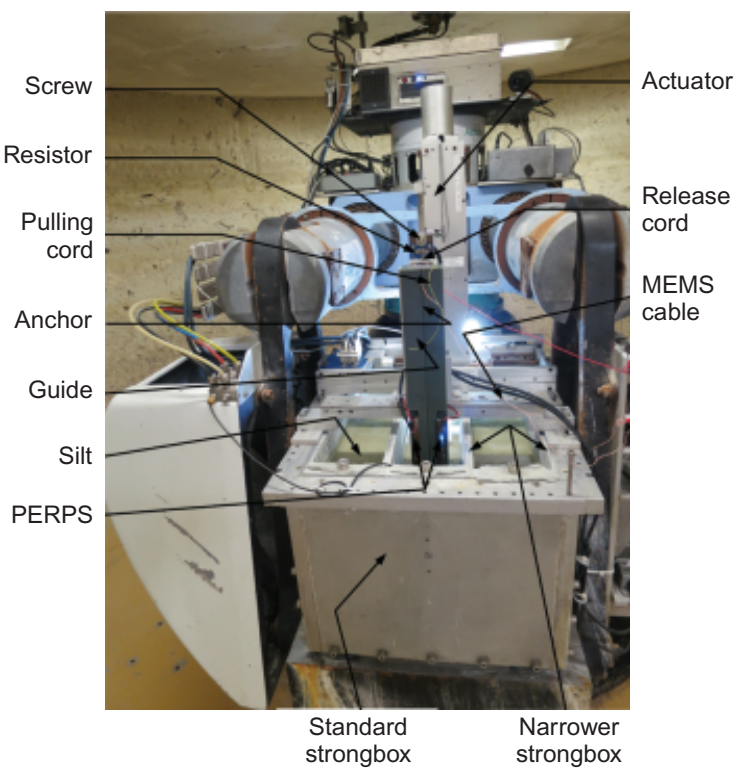

(a)

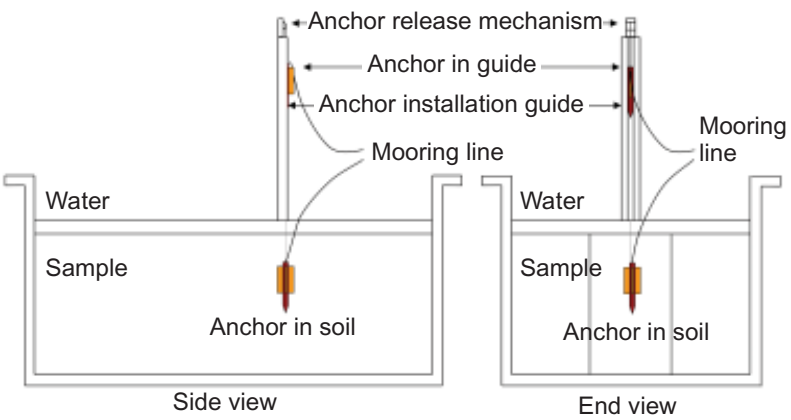

(b)

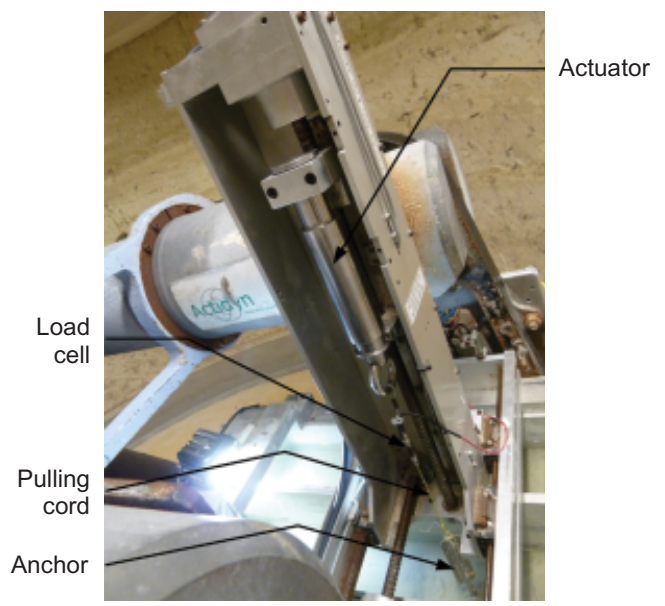

(c)

Fig. 2. Experimental arrangement: (a) photograph of anchor installation; (b) schematic representation of anchor installation; (c) anchor vertical pullout

mounted within the standard strongbox (see Fig. 2). The presence of a radial acceleration field limited anchor installation sites to the longitudinal centreline of the beam centrifuge strongbox (i.e. in the same direction as the axis of rotation in the centrifuge). Using three narrower internal sample boxes facilitated a greater test plan area by interchanging the sample boxes so that the 'test box' was in the middle.

In a centrifuge the acceleration level increases with radius. The acceleration level of $133 \cdot 3 \mathrm{~g}$ for testing was set at an 
effective radius of $1.585 \mathrm{~m}$, equivalent to one-third of the $32 \mathrm{~m}$ sample height, measured from the sample surface. The influence of the non-uniform acceleration field was accounted for in the interpretation of the anchor tests.

Note, for the remainder of the paper, data in equivalent prototype scale or in normalised/dimensionless form will be used, with the exception of the model penetrometers as they are not scaled versions of the equivalent prototype tool.

\section{Model anchor}

Tests were performed using a model torpedo anchor consisting of a solid shaft with a conical tip (angle $\left.\beta_{\text {tip }}=30^{\circ}\right)$ and four rectangular vertical fins $\left(D_{\mathrm{A}}=1.07 \mathrm{~m}\right.$, $L_{\mathrm{A}}=17 \mathrm{~m}$ in prototype scale at $133.3 \mathrm{~g}$; Table 1 ), as shown in Fig. 1(b). The model is made from stainless steel. Table 1 summarises the anchor geometry in model and prototype scale. The overall geometry and prototype scale is the same as the T-98 torpedo anchor used in the Campos Basin (as described by Medeiros (2002), de Araujo et al. (2004) and Brandão et al. (2006)), but with a prototype mass of $126 \cdot 8 \mathrm{t}$, $29 \%$ higher than the T-98 anchor. The increase in mass is consistent with industry designs for calcareous soils, where additional mass is considered to be required to overcome the higher strength of calcareous sediments.

O'Loughlin et al. (2014) demonstrated the merit of miniature accelerometers for measuring the acceleration trace of a dynamically installed anchor during free-fall and dynamic embedment in the centrifuge. This approach was adopted here with a $\pm 500 \mathrm{~g}$ micro-electro mechanical system (MEMS) accelerometer embedded in epoxy resin in a void created in the anchor shaft $6 \mathrm{~mm}$ below the base of the fins (see Fig. 1(b)).

\section{Anchor installation guide and release mechanism}

The method for achieving dynamic installation in the centrifuge was identical to that described in detail by O'Loughlin et al. (2004) and Hossain et al. (2014), and only a brief description is provided here. Anchor embedment was achieved by allowing the anchor to free-fall in the elevated acceleration field in the centrifuge through an installation guide. The guide counteracted the Coriolis effects caused by the rotational movement of the centrifuge, which would cause the anchor to deviate from a vertical orientation during free-fall.

An anchor release cord attached to the top of the anchor kept the anchor at a predetermined drop height in the guide (see Figs 2(a) and 2(b)). Anchor release was achieved inflight using a resistor which, when powered, heated and

Table 1. Model and prototype anchor dimensions

\begin{tabular}{l|c|c|c}
\hline Quantity & Symbol & Model & Prototype* \\
\hline Anchor length & $L_{\mathrm{A}}$ & $127.50 \mathrm{~mm}$ & $17.00 \mathrm{~m}$ \\
Anchor diameter & $D_{\mathrm{A}}$ & $8.03 \mathrm{~mm}$ & $1.07 \mathrm{~m}$ \\
Tip length & $L_{\mathrm{T}}$ & $14.92 \mathrm{~mm}$ & $1.99 \mathrm{~m}$ \\
Fin length & $L_{\mathrm{F}}$ & $75.00 \mathrm{~mm}$ & $10 \cdot 00 \mathrm{~m}$ \\
& $L_{\mathrm{F}, 1}, L_{\mathrm{F}, 3}$ & $3.75 \mathrm{~mm}$ & $0 \cdot 50 \mathrm{~m}$ \\
& $L_{\mathrm{F}, 2}$ & $67.52 \mathrm{~mm}$ & $9.00 \mathrm{~m}$ \\
Fin width & $w_{\mathrm{F}}$ & $6.75 \mathrm{~mm}$ & $0.90 \mathrm{~m}$ \\
Fin thickness & $t_{\mathrm{F}}$ & $0.75 \mathrm{~mm}$ & $0 \cdot 10 \mathrm{~m}$ \\
Dry weight & $W_{\mathrm{d}}$ & $0.53 \mathrm{~N}$ & $1244 \mathrm{kN}$ \\
Submerged weight in water & $W_{\mathrm{s}}$ & $0.45 \mathrm{~N}$ & $1070 \mathrm{kN}$ \\
\hline
\end{tabular}

* At $133 \cdot 3 \mathrm{~g}$.

$\dagger W_{\mathrm{d}}=1098 \mathrm{kN}$ at impact with the seabed (i.e. corresponds to the $g$-level at the soil surface). subsequently burned through the anchor release cord, triggering the anchor drop.

Measurement of the anchor velocity as the anchor approached the soil surface was achieved using eight photo emitter receiver pairs (PERPS), located $17.5 \mathrm{~mm}$ from the exit point and $12.5 \mathrm{~mm}$ apart (see Fig. 2(a)). A metallic protrusion from one of the anchor fins (see Fig. 1(b)) travelling through the guide slot during free-fall would temporarily interrupt each PERP signal. The time between the rising edge of consecutive PERP signals together with the fixed PERP spacing of $12.5 \mathrm{~mm}$ allowed the instantaneous velocity of the anchor to be determined at seven locations (see later results section on 'Anchor velocity and embedment depth'). Numerical integration of the MEMS acceleration data yielded velocity (single integration) and position (double integration), allowing the velocity of the anchor to be determined both during free-fall and as it penetrated the soil (O'Loughlin et al., 2014). This also allowed the final embedment depth of the anchor to be determined and this was verified by direct measurements taken at $1 g$ just after anchor installation. Note, the centrifuge was ramped down after each anchor installation.

\section{Pulling device}

The capacity of the anchor was measured by extracting the anchor by way of a model mooring line connected between the top (referred to as the padeye) of the anchor and the vertical axis of the actuator. Anchor capacity was measured by a $500 \mathrm{~N}$ load cell (see Fig. 2(c)) mounted inline with the mooring line close to the actuator. For inclined loading the mooring line was connected to the actuator by way of a pulley, which allowed adjustment of the loading angle.

\section{Sample preparation}

The anchor tests were performed in samples of calcareous silt $\left(D_{50}=\sim 3 \mu \mathrm{m}\right.$; clay: $30 \%$; liquid limit, $L L=87 \%$; plastic limit, $\left.\mathrm{PL}=37 \% ; G_{\mathrm{s}}=2.73\right)$. The silt was sieved through a $2 \mathrm{~mm}$ sieve to remove any shell fragments and subsequently mixed under a vacuum with fresh water to reconstitute a slurry at a moisture content of about $130 \%$ (about 1.5 times the liquid limit).

The slurry was then poured into the three narrow sample boxes lined with a drainage blanket. The three boxes were placed side by side in a standard strongbox, which was transferred to the beam centrifuge and the samples were consolidated in-flight at $133 \cdot 3 \mathrm{~g}$ for 5 days. A T-bar penetrometer test was then conducted in each sample to ensure that the strength profile increased linearly with depth, indicating that consolidation was complete. The top $0.9 \mathrm{~m}$ was then manually trimmed off the samples at $1 g$ using a custom-designed scraper, taking care to minimise disturbance to the remaining silt. This resulted in a perfectly flat sample surface and a mudline strength greater than $0 \mathrm{kPa}$. The sample was then respun to $133 \cdot 3 \mathrm{~g}$ for a period of about $24 \mathrm{~h}$ before commencing further strength characterisation tests as described below. The final thickness of each sample prior to testing was about $32 \mathrm{~m}$. At all stages during the tests (consolidation, sample trimming and testing), a nominal $1 \mathrm{~m}$ layer of water was maintained at the sample surface to ensure saturation.

\section{Soil characterisation}

Characterisation tests (as illustrated in Fig. 3(a)) were carried out in-flight using a model T-bar penetrometer, with model dimensions $5 \mathrm{~mm}$ in diameter and $20 \mathrm{~mm}$ long (see 


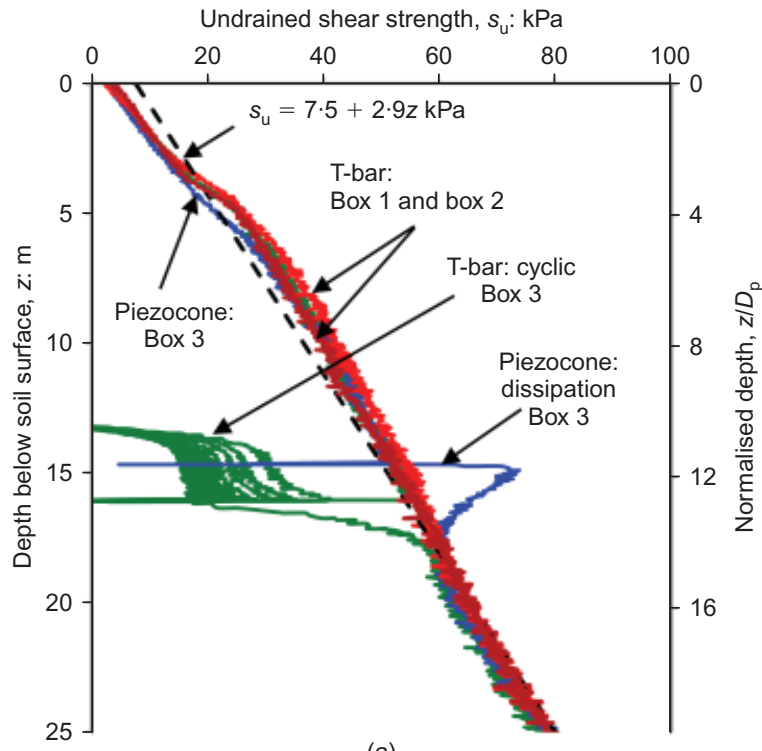

(a)

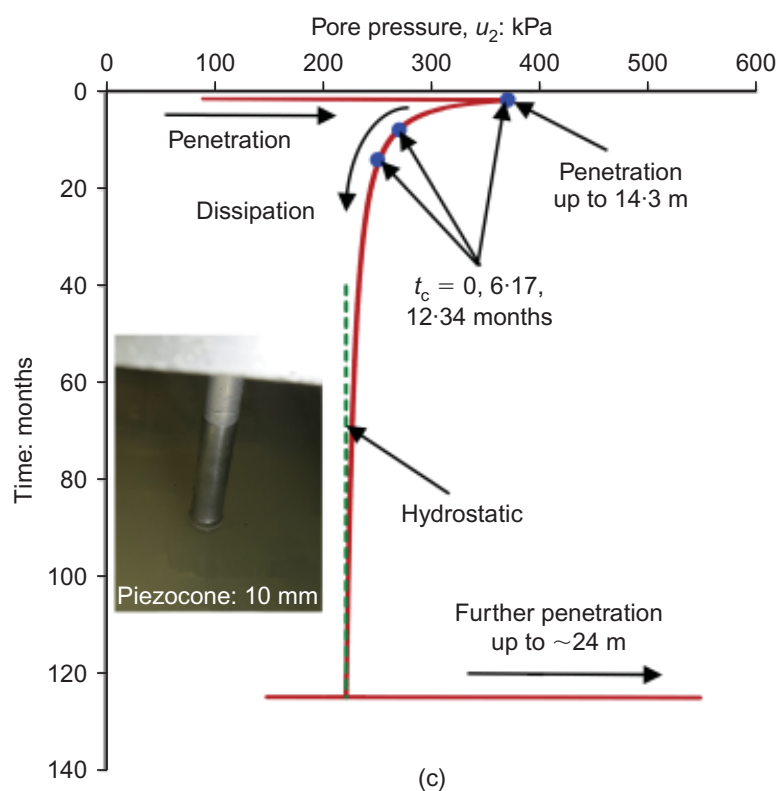

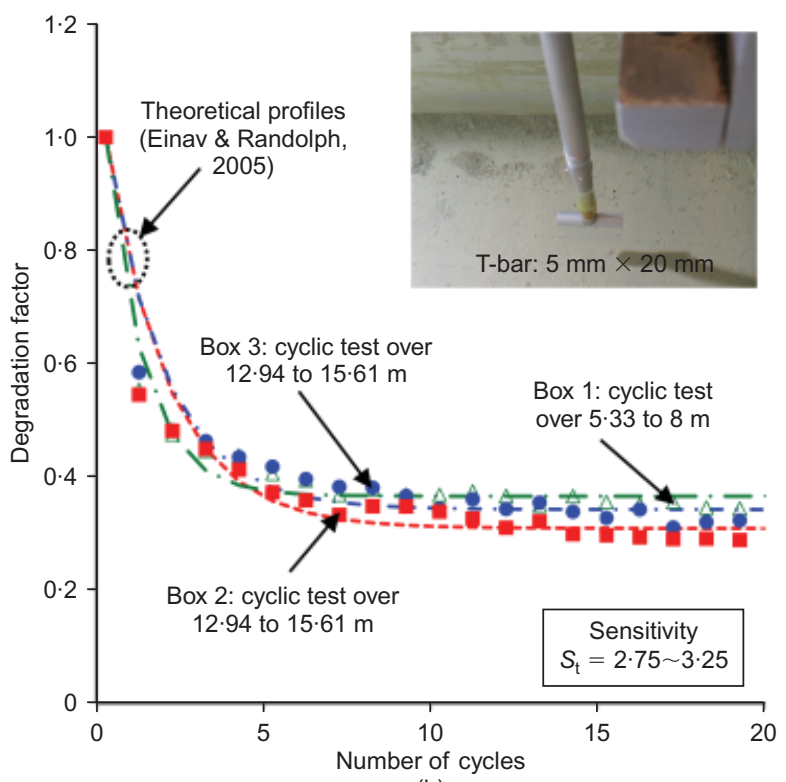

(b)

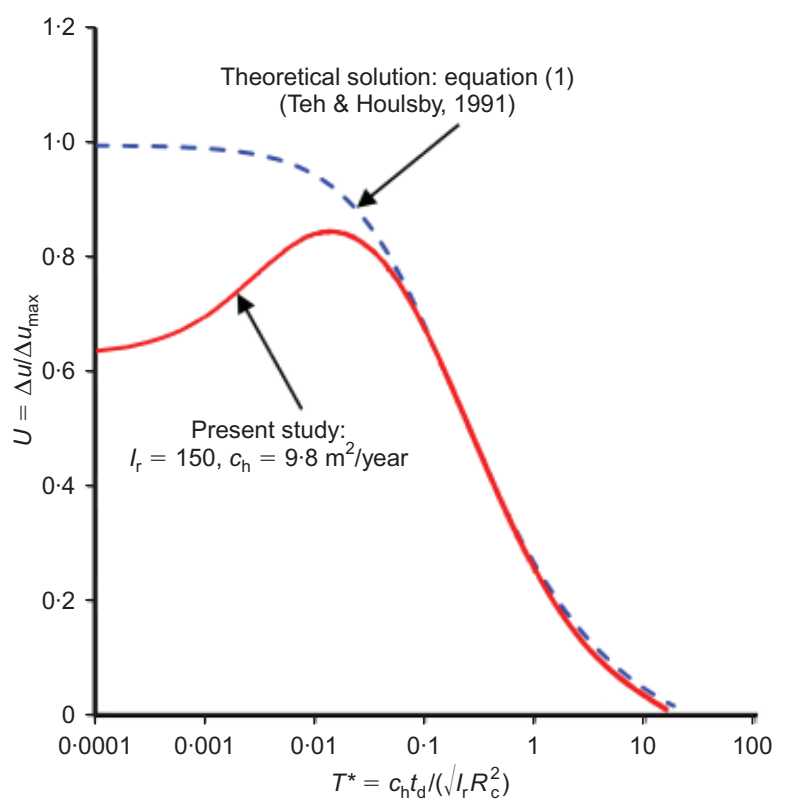

(d)

Fig. 3. Results from soil characterisation tests using T-bar and piezocone: (a) undrained shear strength profiles; (b) undrained shear strength degradation during T-bar cyclic sequence; $(c)$ pore-water pressure $\left(u_{2}\right.$ position) during piezocone test; (d) interpretation of $c_{\mathrm{h}}$ from piezocone dissipation data

insert of Fig. 3(b)), and a model piezocone penetrometer, with a diameter of $10 \mathrm{~mm}$ in model scale (see insert of Fig. 3(c)). The T-bar and piezocone were penetrated at $v=3 \mathrm{~mm} /$ $\mathrm{s}$ and $1.5 \mathrm{~mm} / \mathrm{s}$ respectively, giving a dimensionless velocity $V=v D / c_{\mathrm{V}} \sim 394>30$ (where an average value of the vertical coefficient of consolidation, $c_{\mathrm{v}}$, over the effective stress range associated with the penetration distance was obtained as $1.2 \mathrm{~m}^{2} /$ year from separate consolidation tests), ensuring undrained conditions (Finnie \& Randolph, 1994). T-bar tests were conducted before and after the anchor tests in each sample, although there were no noticeable differences in the strength profiles over the course of the testing. A typical shear strength profile for each sample is plotted in Fig. 3(a). In addition to accounting for the non-uniform acceleration field with sample depth, the measured T-bar resistance at shallow embedment was interpreted using the analysis meth- od suggested by White et al. (2010). This method accounts for changes in soil buoyancy and the reduced bearing factor mobilised during shallow embedment. For the silt samples considered here, shallow embedment effects prevailed to $z=3.4 \mathrm{~m}$, beyond which the undrained shear strength was interpreted using the commonly adopted (deep) bearing factor of $N_{\mathrm{T} \text {-bar }}=10 \cdot 5$. The shear strength profile derived from the piezocone resistance data also accounted for the variation in acceleration level with sample depth, but was deduced using a constant bearing factor of $N_{\mathrm{kt}}=13 \cdot 56$ (Low et al., 2010). The profile as shown on Fig. 3(a) is in good agreement with the T-bar strength profiles. The deduced shear strength profiles were consistent across the three samples and can be idealised as $s_{\mathrm{u}}=7 \cdot 5+2 \cdot 9 z \mathrm{kPa}$. Effective unit weight profiles derived from the water content measurements were found to be consistent between samples and 
increased linearly with sample depth according to $\gamma^{\prime}=6 \cdot 1+0 \cdot 02 z \mathrm{kN} / \mathrm{m}^{3}$.

In addition to the standard T-bar tests, cyclic remoulding T-bar tests were undertaken in each sample to provide an assessment of the fully remoulded strength and hence the sensitivity of the soil. These cyclic remoulding tests were conducted at a sample depth of either $7.06 \mathrm{~m}$ (box 1) or $14.67 \mathrm{~m}$ (boxes 2 and 3 ) and involved cycling the T-bar by \pm 2 T-bar diameters over 20 cycles. The results from the cyclic T-bar tests provided insight into the degradation of the soil, as plotted against number of cycles in Fig. 3(b), together with the theoretical degradation response calculated using the method suggested by Einav \& Randolph (2005), which indicates that the sensitivity of the soil is $S_{\mathrm{t}}=2 \cdot 75 \sim 3 \cdot 25$.

A piezocone penetration test with pore pressure dissipation (measured at the $u_{2}$ position, i.e. at the piezocone shoulder) was carried out at a sample depth of $14.67 \mathrm{~m}$ in box 3. The pore pressure dissipation data (see Fig. 3(d)) were used to determine the coefficient of (as appropriate) horizontal consolidation $\left(c_{\mathrm{h}}\right)$ by matching the test data with the Teh \& Houlsby (1991) theoretical solution

$$
\begin{aligned}
U & =\frac{\Delta u}{\Delta u_{\max }}=\left(0.85+10 T^{*}\right)^{-0.45}-0.08 \\
\text { where } T^{*} & =\frac{c_{\mathrm{h}} t_{\mathrm{d}}}{\sqrt{I_{\mathrm{r}} R_{\mathrm{c}}^{2}}}
\end{aligned}
$$

where $U$ is the normalised excess pore pressure and the rigidity index $I_{\mathrm{r}}$ of $\sim 150$ corresponding to the average shear modulus $\left(G_{50}\right)$ was derived from simple shear test data. The initial rise in pore pressure in Fig. 3(d) reflects the fact that the pore pressure registered at the $u_{2}$ location (at the piezocone shoulder) was lower than that on the cone face. This has recently been shown to be due to unloading effects for soil elements moving from the vicinity of the cone face to the cone shoulder (Chai et al., 2012). When penetration was stopped the pore pressure would have initially increased (due to local equalisation of the high pore pressure gradient around the piezocone tip) prior to dissipating (Campanella et al., 1986). However, the pore pressure response agrees well with the theoretical solution for $T^{*} \geqslant 0.04$, with the best agreement obtained using $c_{\mathrm{h}}=9.8 \mathrm{~m}^{2} /$ year.

\section{Anchor testing procedure}

The anchor installation guide was mounted on the strongbox and the anchor was inserted in the guide at the required drop height. The centrifuge package was then respun at $133.3 \mathrm{~g}$ for 12.34 months before dropping the anchor. After anchor installation the centrifuge was ramped down so a direct measurement of the embedment could be made and to connect the mooring line to the actuator in preparation for the anchor pullout. The actuator position was adjusted to achieve the required mudline load inclination $\theta_{0}$ before respinning the centrifuge to $133 \cdot 3 \mathrm{~g}$. A varying reconsolidation period was permitted before extracting the anchor at a rate of $v=1 \mathrm{~mm} / \mathrm{s}$ to measure the monotonic anchor capacity. This rate was selected such that the dimensionless velocity during extraction, $V=v D_{\mathrm{A}} / c_{\mathrm{V}} \approx 211>30$, which was expected to be sufficient to ensure undrained conditions (Finnie \& Randolph, 1994).

In total, 15 anchor installation and pullout tests were performed in three sample boxes (B1, B2, B3; see Table 2 and Fig. 4). Adjacent anchor sites had $13.3 \mathrm{~m}$ centre-tocentre spacing and were $12.7 \mathrm{~m}$ from the strongbox walls. The tests in B3 were carried out in a slightly different pattern to accommodate the increased soil disturbance due to the two pullout tests at $\theta_{0}=0$ and $15^{\circ}$ (see box B3, Fig. 4).

\section{RESULTS AND DISCUSSION: ANCHOR INSTALLATION Anchor velocity and embedment depth}

The anchor velocity at impact was determined from the velocity profile established from the PERPs and from the MEMS accelerometer data (see Fig. 5). The impact velocities achieved in the tests were in the range 16.6 to $21.2 \mathrm{~m} / \mathrm{s}$, and increased with increasing drop height (see Table 2 and Fig. 6).

The embedment depths from all tests are plotted in Fig. 6, and as expected increase with increasing impact velocity. In this calcareous silt with undrained shear strength $s_{\mathrm{u}}=7 \cdot 5+2 \cdot 9 z \mathrm{kPa}$, the anchor tip embedment $\left(d_{\mathrm{e}, \mathrm{t}}\right)$ ranges from 0.96 to $1 \cdot 1 L_{\mathrm{A}}$. For a torpedo anchor with similar geometry, a similar range of impact velocity $\left(v_{\mathrm{i}}=15 \sim 22 \mathrm{~m} / \mathrm{s}\right)$ and in calcareous silt with $s_{\mathrm{u}}=2+3 z \mathrm{kPa}$, Hossain et al. (2014) reported embedment depths in the range $1 \cdot 17 \sim 1 \cdot 4 L_{\mathrm{A}}$. The $18 \sim 21 \%$ lower normalised embedment depths for the tests reported here are partly due to a combination of geometrical

\begin{tabular}{|c|c|c|c|c|c|c|c|c|c|c|c|c|c|}
\hline \multirow[t]{2}{*}{ Box } & \multirow[t]{2}{*}{ Test } & \multirow{2}{*}{$\begin{array}{c}\begin{array}{c}\text { Drop } \\
\text { height, } h_{\mathrm{d}}\end{array} \\
\begin{array}{c}\text { Model: } \\
\text { mm }\end{array}\end{array}$} & \multirow[t]{2}{*}{$h_{\mathrm{d}} / D_{\mathrm{p}}$} & \multirow{2}{*}{$\begin{array}{c}\text { Impact velocity, } \\
v_{\mathrm{i}} \\
\text { Model }= \\
\text { Prototype: } \mathrm{m} / \mathrm{s}\end{array}$} & \multicolumn{2}{|c|}{ Tip embedment, $d_{\mathrm{e}, \mathrm{t}}$} & \multirow[t]{2}{*}{$d_{\mathrm{e}, \mathrm{t}} / D_{\mathrm{p}}$} & \multicolumn{2}{|c|}{$\begin{array}{l}\text { Time allowed for } \\
\text { consolidation, } t_{\mathrm{c}}^{\dagger}\end{array}$} & \multirow{2}{*}{$\begin{array}{c}\text { Mudline load } \\
\text { inclination, } \\
\theta_{0} \text { : degrees }\end{array}$} & \multicolumn{3}{|c|}{ Holding capacity } \\
\hline & & & & & $\begin{array}{l}\text { Model: } \\
\mathrm{mm}\end{array}$ & $\begin{array}{l}\text { Prototype: } \\
\mathrm{m}^{*}\end{array}$ & & $\begin{array}{l}\text { Model: } \\
\min \end{array}$ & $\begin{array}{l}\text { Prototype: } \\
\text { months }\end{array}$ & & $F: \mathrm{kN}$ & $F_{\mathrm{N}}: \mathrm{kN}$ & $F / W_{\mathrm{d}}$ \\
\hline \multirow[t]{5}{*}{ B1 } & $\mathrm{T} 1$ & $252 \cdot 0$ & $26 \cdot 5$ & $21 \cdot 23$ & $139 \cdot 5$ & $18 \cdot 7$ & $14 \cdot 8$ & 30 & $12 \cdot 34$ & 90 & 3056 & 2097 & $2 \cdot 46$ \\
\hline & $\mathrm{T} 2$ & $247 \cdot 0$ & $26 \cdot 0$ & $20 \cdot 95$ & $138 \cdot 7$ & $18 \cdot 6$ & $14 \cdot 7$ & 30 & $12 \cdot 34$ & 90 & 3001 & 2042 & $2 \cdot 41$ \\
\hline & $\mathrm{T} 3$ & $215 \cdot 5$ & $22 \cdot 7$ & $19 \cdot 26$ & $134 \cdot 0$ & $17 \cdot 9$ & $14 \cdot 1$ & 30 & $12 \cdot 34$ & 90 & 2851 & 1892 & $2 \cdot 29$ \\
\hline & $\mathrm{T} 4$ & $215 \cdot 0$ & $22 \cdot 6$ & $19 \cdot 17$ & $134 \cdot 0$ & $17 \cdot 9$ & $14 \cdot 1$ & 30 & $12 \cdot 34$ & 90 & 2840 & 1881 & $2 \cdot 28$ \\
\hline & $\mathrm{T} 5$ & $212 \cdot 0$ & $22 \cdot 3$ & $19 \cdot 15$ & $133 \cdot 9$ & $17 \cdot 9$ & $14 \cdot 1$ & 30 & $12 \cdot 34$ & 90 & 2837 & 1767 & $2 \cdot 28$ \\
\hline \multirow[t]{5}{*}{ B2 } & T6 & $247 \cdot 0$ & $26 \cdot 0$ & $20 \cdot 93$ & $138 \cdot 5$ & $18 \cdot 5$ & $14 \cdot 6$ & 30 & $12 \cdot 34$ & 90 & 2989 & 2030 & $2 \cdot 40$ \\
\hline & $\mathrm{T} 7$ & $195 \cdot 0$ & $20 \cdot 5$ & $18 \cdot 20$ & $130 \cdot 5$ & $17 \cdot 4$ & $13 \cdot 7$ & 30 & $12 \cdot 34$ & 90 & 2719 & 1760 & $2 \cdot 19$ \\
\hline & T8 & $175 \cdot 0$ & $18 \cdot 4$ & $17 \cdot 54$ & $127 \cdot 5$ & $17 \cdot 0$ & $13 \cdot 4$ & 30 & $12 \cdot 34$ & 90 & 2575 & 1616 & $2 \cdot 07$ \\
\hline & T9 & $159 \cdot 0$ & $16 \cdot 7$ & $16 \cdot 56$ & $123 \cdot 5$ & $16 \cdot 4$ & $13 \cdot 0$ & 30 & $12 \cdot 34$ & 90 & 2331 & 1371 & $1 \cdot 87$ \\
\hline & T10 & $235 \cdot 5$ & $24 \cdot 8$ & $20 \cdot 31$ & $137 \cdot 0$ & $18 \cdot 3$ & $14 \cdot 5$ & 30 & $12 \cdot 34$ & 90 & 2962 & 2002 & $2 \cdot 38$ \\
\hline \multirow[t]{5}{*}{ B3 } & T11 & $235 \cdot 5$ & $24 \cdot 8$ & $20 \cdot 18$ & $136 \cdot 8$ & $18 \cdot 3$ & $14 \cdot 5$ & 30 & $12 \cdot 34$ & 90 & 2911 & 1953 & $2 \cdot 34$ \\
\hline & T12 & $235 \cdot 5$ & $24 \cdot 8$ & $20 \cdot 13$ & $136 \cdot 5$ & $18 \cdot 3$ & $14 \cdot 5$ & 0 & 0 & 90 & 2477 & 1518 & 1.99 \\
\hline & T13 & $232 \cdot 0$ & $24 \cdot 4$ & 19.99 & $136 \cdot 3$ & $18 \cdot 2$ & $14 \cdot 4$ & 15 & $6 \cdot 17$ & 90 & 2831 & 1872 & $2 \cdot 28$ \\
\hline & T14 & $232 \cdot 0$ & $24 \cdot 4$ & $19 \cdot 88$ & $136 \cdot 2$ & $18 \cdot 2$ & $14 \cdot 4$ & 30 & $12 \cdot 34$ & 0 & 4087 & 3129 & $3 \cdot 29$ \\
\hline & T15 & $232 \cdot 0$ & $24 \cdot 4$ & $19 \cdot 76$ & $136 \cdot 1$ & $18 \cdot 2$ & $14 \cdot 4$ & 30 & $12 \cdot 34$ & 15 & 4048 & 3089 & $3 \cdot 25$ \\
\hline
\end{tabular}

Table 2. Summary of centrifuge model tests conducted

* Accounting for variation in acceleration level with sample depth.

$\dagger$ Excluding time required for centrifuge ramp down, test procedures at $1 \boldsymbol{g}$ and centrifuge ramp up to $133 \cdot 3 \mathrm{~g}$. 
82

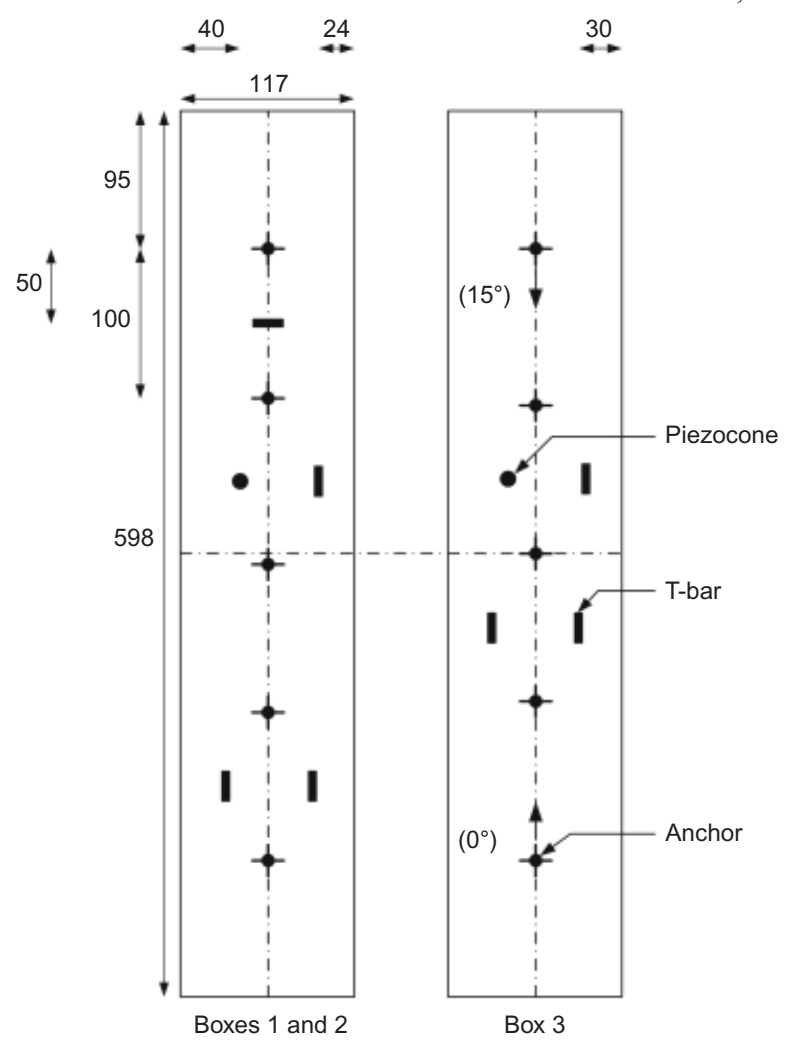

Fig. 4. Layout of centrifuge model tests conducted (dimensions in mm)

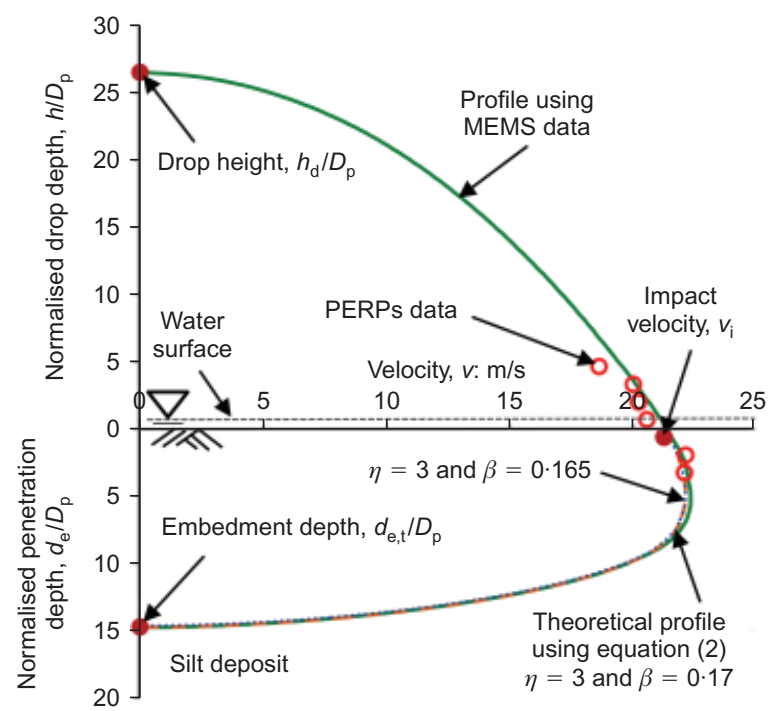

Fig. 5. Torpedo anchor installation: measured data and theoretical prediction $\left(v_{\mathrm{i}}=\mathbf{2 1} \cdot 23 \mathrm{~m} / \mathrm{s}\right)$

and mass differences between the anchors in these two studies and partly due to the $5.5 \mathrm{kPa}$ higher mudline strength intercept. However, as will be shown later, all data show consistent trends when plotted in terms of dimensionless total energy and embedment depth, effectively removing the dependence of these variables. The embedment depths achieved in these tests and those reported by Hossain et al. (2014) are significantly lower than the $1 \cdot 5 \sim 2 \cdot 1 L_{\mathrm{A}}$ range reported by Medeiros (2002) and Brandão et al. (2006) for geometrically similar but lighter T-98 torpedo anchor in clay at the Campos basin $\left(s_{\mathrm{u}}=5+2 z\right.$ $\mathrm{kPa}$ ), which reflects the lower embedment potential for these anchors in silt, due to the higher strength gradient and other reasons discussed in the later section on 'Theoretical prediction'.

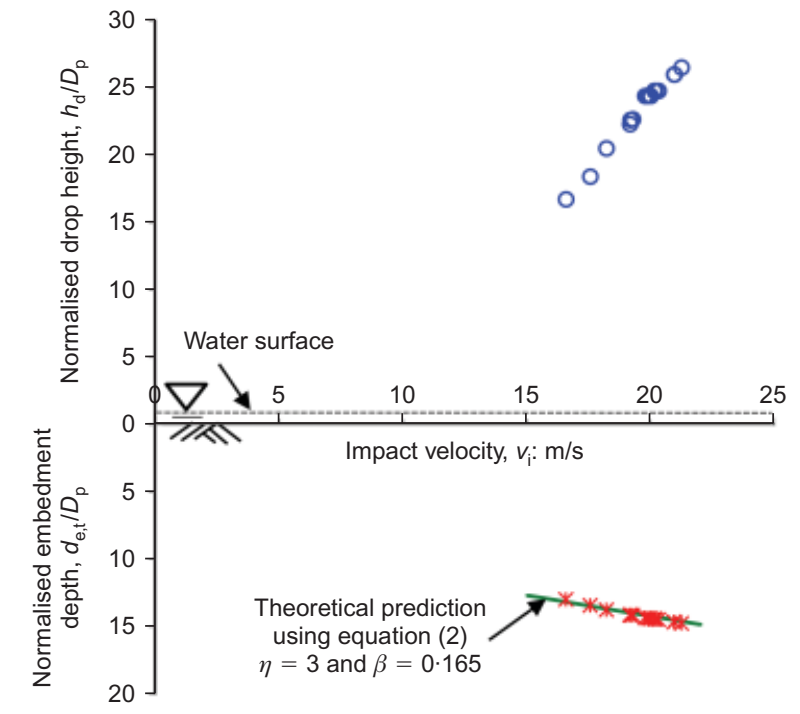

Fig. 6. Effect of drop height on impact velocity and anchor embedment depth

Installation mechanism: cavity condition

The degree of hole closure during dynamic embedment has implications for the resistance acting on the anchor during installation and extraction. Observations during installation (from a camera mounted on the centrifuge strongbox) together with photographs taken of the impact site after installation showed that soil backflow occurred into the cavities formed by the passage of the anchor shaft and fins, with a slight crater on the soil surface. However, and as discussed in detail by O'Loughlin et al. (2013), it is unclear if hole closure occurred within the $10 \sim 15 \mathrm{~ms}$ taken for dynamic installation in the centrifuge.

\section{Theoretical prediction}

Shear resistance method. The motion response of a torpedo anchor during dynamic embedment in soil may be approached by considering Newton's second law of motion and the forces acting on the anchor during penetration. Several studies (e.g. True, 1974; O’Loughlin et al., 2013) have adopted such an approach, with variations on the inclusion and formulation of the various forces acting on the torpedo anchor. A similar approach is adopted here

$$
\begin{aligned}
m \frac{\mathrm{d}^{2} z}{\mathrm{~d} t^{2}}= & W_{\mathrm{d}}-F_{\gamma}-R_{\mathrm{f}}\left(F_{\mathrm{b}}+F_{\mathrm{f}}\right) \\
= & W_{\mathrm{d}}-F_{\gamma}-R_{\mathrm{f}}\left(F_{\mathrm{b}, \mathrm{bA}}+F_{\mathrm{b}, \mathrm{bF}}+F_{\mathrm{fA}}+F_{\mathrm{fF}}\right) \\
= & W_{\mathrm{d}}-F_{\gamma}-R_{\mathrm{f}}\left(N_{\mathrm{c}, \mathrm{bA}} \mathrm{s}_{\mathrm{u}, \mathrm{bA}} A_{\mathrm{A}}+N_{\mathrm{c}, \mathrm{bF}} \mathrm{s}_{\mathrm{u}, \mathrm{bF}} A_{\mathrm{bF}}\right. \\
& \left.+\alpha s_{\mathrm{u}, \mathrm{sA}} A_{\mathrm{sA}}+\alpha s_{\mathrm{u}, \mathrm{sF}} A_{\mathrm{sF}}\right)
\end{aligned}
$$

The frictional resistance term $\left(F_{\mathrm{f}}\right)$ comprises friction along the shaft $\left(F_{\mathrm{fA}}\right)$ and the fins $\left(F_{\mathrm{fF}}\right)$, whereas the bearing resistance term $\left(F_{\mathrm{b}}\right)$ comprises end bearing at the base of the shaft $\left(F_{\mathrm{b}, \mathrm{bA}}\right)$ and fins $\left(F_{\mathrm{b}, \mathrm{bF}}\right)$. As discussed previously, soil backflow was observed after installation. However, as it is unlikely that this occurred during dynamic installation (O'Loughlin et al., 2013), reverse end bearing at the upper end of the shaft $\left(F_{\mathrm{b}, \mathrm{tA}}\right)$ and fins $\left(F_{\mathrm{b}, \mathrm{FF}}\right)$ was not considered. $W_{\mathrm{d}}$ is the dry weight of the anchor and $F_{\gamma}$ is a buoyancy force, calculated as the displaced volume times the total unit weight of the soil. Drag resistance, accounted for during dynamic penetration in studies on clay (e.g. O'Loughlin et 
al., 2013) was not considered here due to the relatively high strength of the soil.

Natural fine-grained soils exhibit strain-rate dependency and also soften as they are sheared and remoulded. For dynamic installation of torpedo anchors, the rate dependency of undrained shear strength will dominate the anchor behaviour. There is general agreement that the undrained strength increases with increasing shear strain rate (e.g. Biscontin \& Pestana, 2001; Lunne \& Andersen, 2007). As such, to augment the measured undrained shear strength due to the high strain rates associated with the high anchor penetration velocities, a term $R_{\mathrm{f}}$ is introduced in equation (2). The compensating effect of softening is neglected for anchor installation involving such very high strain rates. Strain rate effects on soil strength are usually accounted for using semilogarithmic or power functions (e.g. Low et al., 2008), with the parameter $R_{\mathrm{f}}$ (neglecting the effect of softening) expressed as

$$
R_{\mathrm{f}}=\left[1+\lambda \log \left(\frac{\dot{\gamma}}{\dot{\gamma}_{\text {ref }}}\right)\right] R_{\mathrm{f}} \geqslant 1
$$

or

$$
R_{\mathrm{f}}=\left(\frac{\dot{\gamma}}{\dot{\gamma}_{\text {ref }}}\right)^{\mu} R_{\mathrm{f}} \geqslant 1
$$

where $\dot{\gamma}$ is the operative shear strain rate, $\dot{\gamma}_{\text {ref }}$ is the reference strain rate at which the undrained shear strength was measured, and $\lambda$ and $\mu$ are strain rate parameters in the semi-logarithmic and power laws respectively.

More recently the Herschel-Buckley model, originating from fluid mechanics, has been used to describe the strainrate dependency of run-out soil from submarine slides (e.g. Zhu \& Randolph, 2011; Boukpeti et al., 2012). A suitable implementation of the Herschel-Buckley model for geotechnical applications may be expressed as (Zhu \& Randolph, 2011)

$$
R_{\mathrm{f}}=\left[1+\eta\left(\frac{\dot{\gamma}}{\dot{\gamma}_{\text {ref }}}\right)^{\beta}\right] \frac{1}{1+\eta} \quad R_{\mathrm{f}} \geqslant 1
$$

where $\eta$ is a viscous property and $\beta$ is the shear-thinning index. For this problem involving high penetration velocities, and given the stronger rate dependency of calcareous silt compared to clay (Boukpeti \& White, 2011), equation (4) is adopted, maintaining consistency with parallel numerical work by two of the current authors and colleagues which is currently under review.

During anchor penetration, the operative shear strain rate varies through the soil body, but it is reasonable to assume that at any given location the operational strain rate may be approximated by the normalised velocity, $v / D_{\mathrm{A}}$ (O'Loughlin et al., 2013). Equation (4) can therefore be expressed as

$$
R_{\mathrm{f}}=\left[1+\eta\left(\frac{v / D_{\mathrm{A}}}{(v / D)_{\text {ref }}}\right)^{\beta}\right] \frac{1}{1+\eta} \quad R_{\mathrm{f}} \geqslant 1
$$

where, owing to geometrical similarity between the piezocone and the torpedo anchor, $(v / D)_{\text {ref }}$ was calculated using the piezocone penetration velocity, $v=1.5 \mathrm{~mm} / \mathrm{s}$ and diameter, $D=10 \mathrm{~mm}$. The anchor velocity profile for test $\mathrm{T} 1$, with an upper bound impact velocity of $v_{\mathrm{i}}=21.2 \mathrm{~m} / \mathrm{s}$, was calculated using equation (2) and equation (5) and is shown in Fig. 5. Again, owing to geometrical similarity between the anchor and the piezocone penetrometer, $N_{\mathrm{c}, \mathrm{bA}}=13.56$ was selected for the anchor tip, whereas the fins were considered analogous to deeply embedded strip footings and, as such, $N_{\mathrm{c}, \mathrm{bF}}=7.5$ was selected for the base of the fins
(O'Loughlin et al., 2013). The coefficient of friction, $\alpha$, was taken as $0 \cdot 24$, as back-analysed from a vertical pullout test with $t_{\mathrm{c}}=0$ (i.e. with no set-up effect, such that $\alpha$ for installation should be similar to that for extraction; see later section on 'Theoretical predictions for vertical loading') and is reasonably close to the inverse of the soil sensitivity of $0 \cdot 30 \sim 0 \cdot 36$. It can be seen that the predicted velocity profile is consistent with the measured velocity profile, established from the MEMS accelerometer measurements, and $\eta=3$ and $\beta=0.17$ provided the best estimate for the measured embedment depth. It was found that, while $\eta=3$ is kept constant, the values of $\beta$ reduce slightly with decreasing impact velocity. As such, the predicted embedment depths shown on Fig. 6 were obtained using an average $\beta=0 \cdot 165$ (and $\eta=3$ ). The corresponding velocity profile is also included in Fig. 5. The back-figured strain rate parameters ( $\eta=3$ and $\beta=0 \cdot 16 \sim 0 \cdot 17$ ) are within the range, $\eta=2 \sim 4$ and $\beta=0 \cdot 15 \sim 0 \cdot 25$, typically measured for calcareous silt (N. Boukpeti, personal communication 2012).

For direct comparison with anchor installation in clay (O'Loughlin et al., 2013), Figs 7(a) and 7(b) plot backfigured values of the strain rate parameters $\lambda$ and $\mu$ (used in the semi-logarithmic and power laws in equations (3a) and (3b), respectively) as functions of $v_{\mathrm{av}} / D_{\mathrm{p}}$ (where $v_{\mathrm{av}}$ is the average anchor velocity during penetration and $D_{\mathrm{p}}$ is the equivalent diameter accounting for the additional projected area from the anchor fins). A very narrow range of $\lambda=0.64 \sim 0.82$ and $\mu=0.14 \sim 0.16$ was obtained over the range $v_{\mathrm{av}} / D_{\mathrm{p}}=1600 \sim 2700 \mathrm{~s}^{-1}$ associated with the torpedo anchor tests considered here. The results from anchor installation in clay (O'Loughlin et al., 2013) are also included in the figures for comparison. The back-figured values of $\lambda$ and $\mu$ for calcareous silt are respectively around $50 \%$ and $35 \%$ higher, which implies that the increase in undrained shear strength, and hence in penetration resistance, per log cycle of penetration velocity or shear strain rate is much higher for calcareous silt than for kaolin clay. This is consistent with rate parameters derived from variable rate T-bar penetration tests in calcareous silt that were $2 \sim 3$ times higher

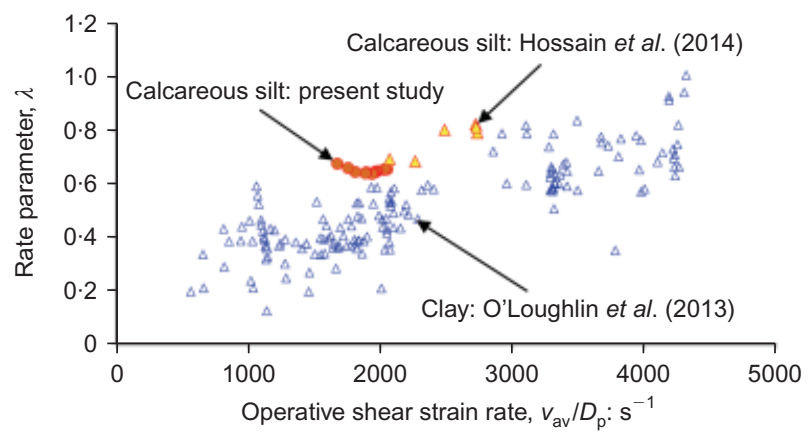

(a)

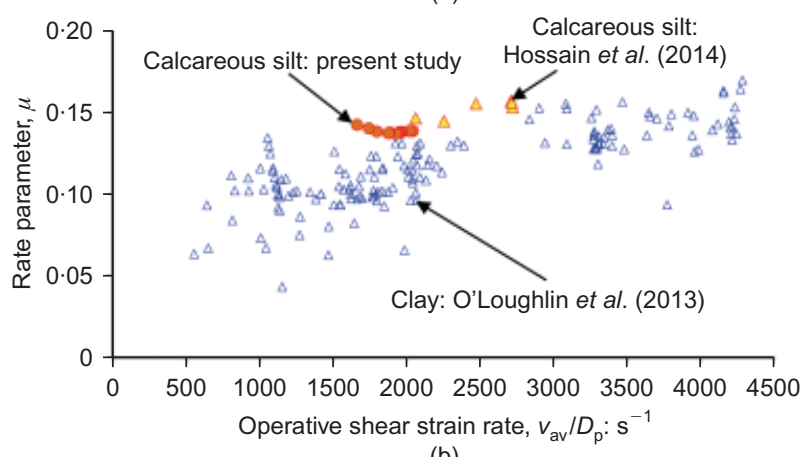

(b)

Fig. 7. Back-figured strain rate parameters: (a) rate parameter $\lambda$ for semi-logarithmic function; (b) rate parameter $\mu$ for power law function 
than those derived from the same tests in kaolin and Burswood clay (Boukpeti \& White, 2011).

Total energy method. O'Loughlin et al. (2013) proposed a simple expression for conservatively estimating the embedment of dynamically installed anchor in clay. Total energy, defined as the sum of the kinetic and potential energy (relative to the final embedment depth) of the anchor at the mudline, and soil strength gradient were expressed in terms of normalised embedment depth as

$$
\frac{d_{\mathrm{e}, \mathrm{t}}}{D_{\mathrm{p}}} \approx\left(\frac{E_{\mathrm{total}}}{k D_{\mathrm{p}}^{4}}\right)^{1 / p}
$$

where

$$
E_{\text {total }}=\frac{1}{2} m v_{\mathrm{i}}^{2}+m^{\prime} \boldsymbol{g} d_{\mathrm{e}, \mathrm{t}}
$$

In equation (7) $\mathrm{m}^{\prime}$ is the effective mass of the anchor (submerged in soil) and $\boldsymbol{g}$ is Earth's gravitational acceleration $=9.81 \mathrm{~m} / \mathrm{s}^{2}$.

Figure 8 compares total energy data for clay reported by O'Loughlin et al. (2013) with corresponding data for calcareous silt. The best fit between the experimental data and equation (6) is obtained using $p=3 \cdot 24$ for calcareous silt, compared with $p=3$ for clay, as originally proposed by O'Loughlin et al. (2013).

An alternative version of equation (6), accounting for anchor total surface area $\left(A_{\mathrm{s}}=A_{\mathrm{SA}}+A_{\mathrm{sF}}\right)$, may be expressed as

$$
\frac{d_{\mathrm{e}, \mathrm{t}}}{D_{\mathrm{p}}} \approx q\left(\frac{E_{\mathrm{total}}}{k A_{\mathrm{s}} D_{\mathrm{p}}^{2}}\right)^{1 / r}
$$

where $q=2.56$ and $r=2.5$ provide an excellent fit to the calcareous silt data, as demonstrated by Fig. 9 .

From Fig. 8, it is clear that the embedment depths achieved in calcareous silt are $18 \cdot 5 \sim 19.5 \%$ shallower than those in clay, even when the undrained shear strength gradient of the soil, $k$, is used in the normalisation. This may be attributed to: $(a)$ the stronger strain rate dependency in calcareous silt compared to clay (as discussed previously, see Fig. 7 and Boukpeti \& White (2011)) and (b) the

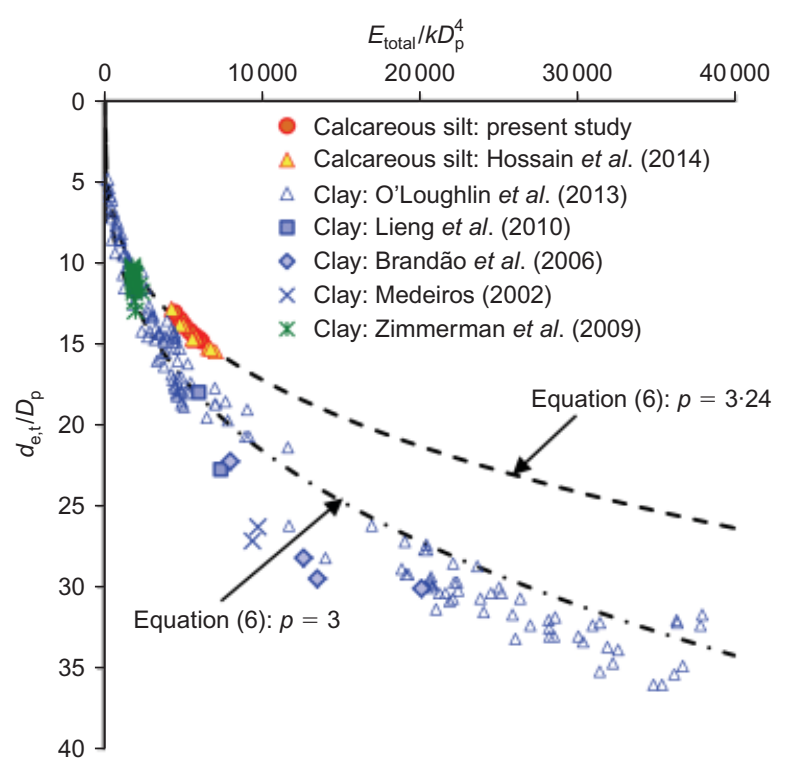

Fig. 8. Total energy-normalised embedment response for calcareous silt and clay

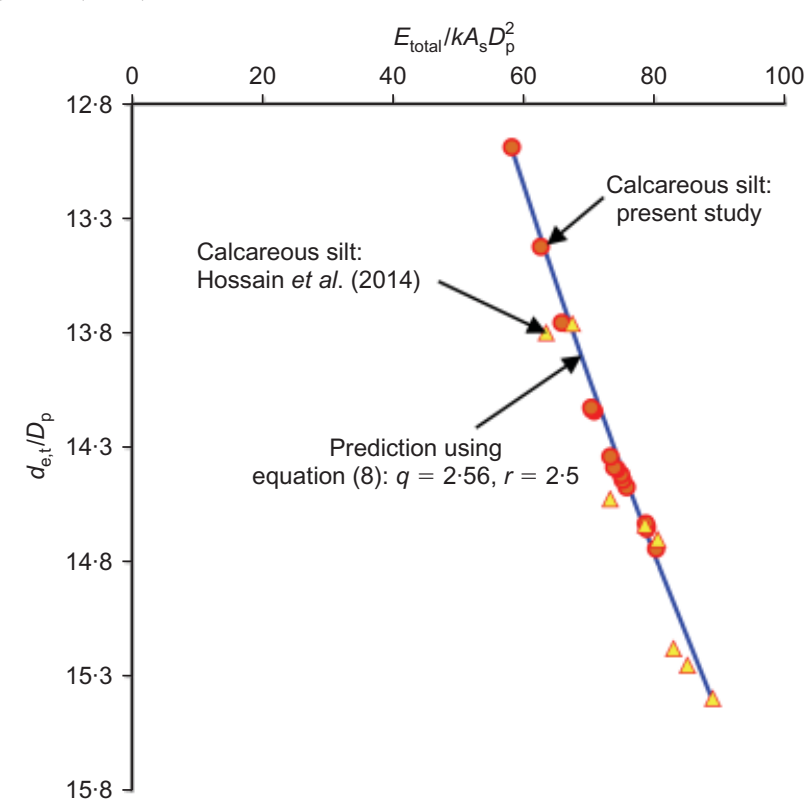

Fig. 9. Prediction for anchor embedment depth in calcareous silt using total energy based expression

dilative behaviour of calcareous silt compared to contractive behaviour of clay (Mao \& Fahey, 2003).

\section{RESULTS AND DISCUSSION: ANCHOR HOLDING CAPACITY \\ Measured vertical pullout resistance}

The extraction responses from the anchor vertical pullout tests are presented in terms of load resistance, $F$, as a function of normalised pullout displacement, $u / D_{\mathrm{p}}$ in Fig. 10. For clarity, only six of the 13 vertical pullout tests (T1, T6, T7, T8, T9, T11) are shown, with results from all tests tabulated in Table 2. The profiles in Fig. 10 show a consistent trend, characterised by a sharp increase in load to an ultimate holding capacity within a displacement of $1 \cdot 4 \sim 1 \cdot 5 D_{\mathrm{p}}$, before reducing rapidly. As explained by Hossain et al. (2014), this indicates that failure is brittle, owing to the absence of anchor rotation under this vertical pullout. Clearly anchor holding capacity increases with increasing $v_{\mathrm{i}}$ and (hence) $d_{\mathrm{e}, \mathrm{t}}$, reflecting the increase in soil strength with anchor embedment depth.

\section{Theoretical predictions for vertical loading}

For assessing quasi-static extraction resistance, two methods have been considered: $(a)$ conventional shear resistance, analogous with the American Petroleum Institute (API) method for driven piles (API, 2007), and (b) a direct piezocone based design method.

Shear resistance method. The monotonic vertical pullout capacity of torpedo anchors can be calculated using a reorganised version of equation (2) that now accounts for bearing resistance at the upper end of the shaft and fins

$$
\begin{aligned}
F_{\mathrm{v}}= & W_{\mathrm{ss}}+R_{\mathrm{f}}\left(N_{\mathrm{c}, \mathrm{bA}} s_{\mathrm{u}, \mathrm{bA}} A_{\mathrm{A}}+N_{\mathrm{c}, \mathrm{tA}} S_{\mathrm{u}, \mathrm{tA}} A_{\mathrm{A}}+N_{\mathrm{c}, \mathrm{bF}} S_{\mathrm{u}, \mathrm{bF}} A_{\mathrm{bF}}\right. \\
& \left.+N_{\mathrm{c}, \mathrm{tF}} s_{\mathrm{u}, \mathrm{tF}} A_{\mathrm{bF}}+\alpha s_{\mathrm{u}, \mathrm{sA}} A_{\mathrm{sA}}+\alpha s_{\mathrm{u}, \mathrm{sF}} A_{\mathrm{sF}}\right)
\end{aligned}
$$

where $W_{\mathrm{sS}}$ is the submerged weight of the anchor in soil. For this quasi-static extraction, the strain rate dependency should 


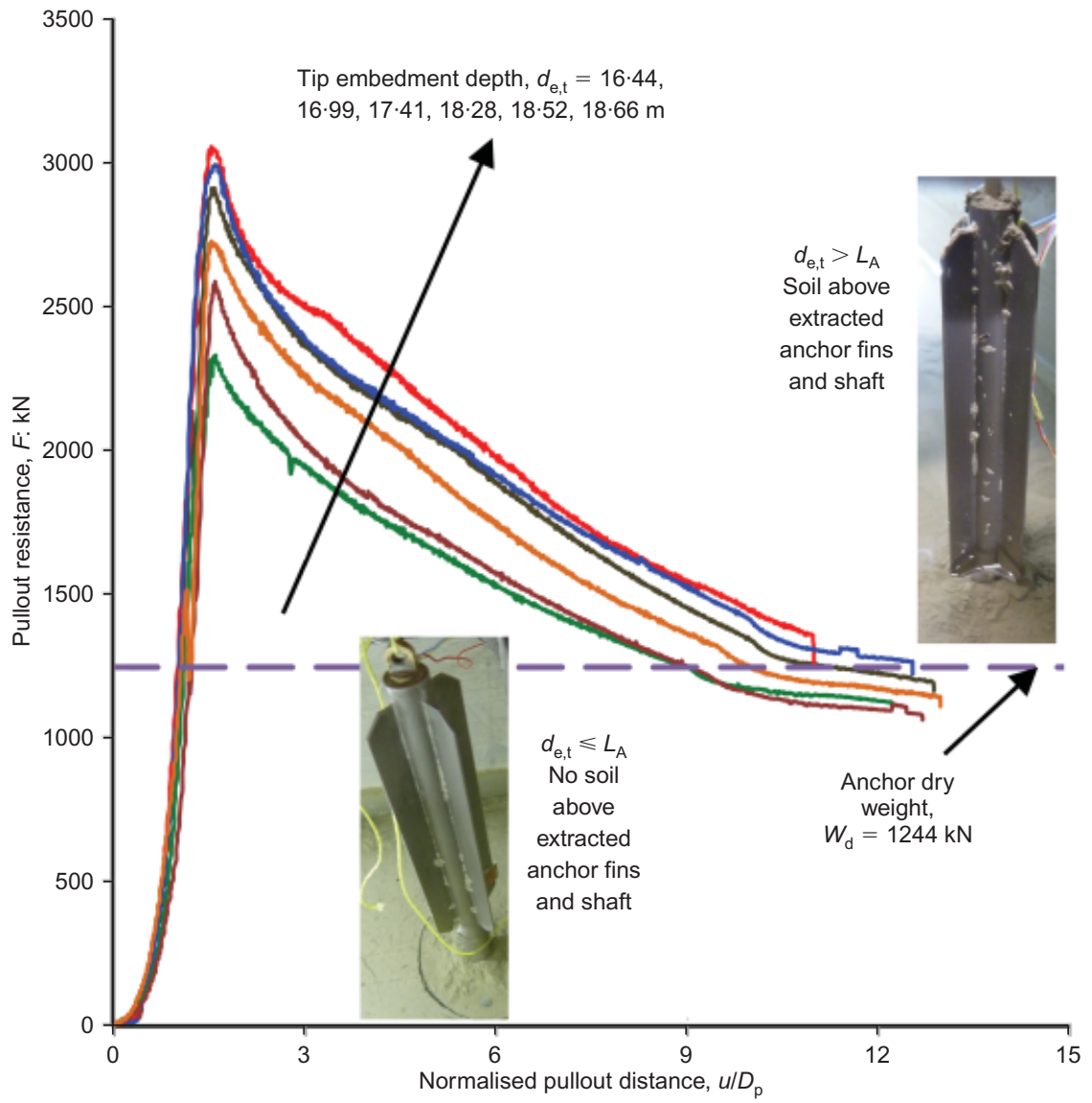

Fig. 10. Effect of anchor embedment depth (and hence drop height and impact velocity) on vertical extraction resistance (tests T1, T2, T7 T9 and T11; Table 2)

be modelled following the semi-logarithmic law presented in equation (3a) (Einav \& Randolph, 2005). However, the approximate operative shear strain rate for the anchor $v / D_{\mathrm{A}}=1 / 8 \cdot 03=0 \cdot 125 \mathrm{~s}^{-1}$ is almost identical to that for the piezocone $\left(0 \cdot 15 \mathrm{~s}^{-1}\right)$. It is also assumed that the effect of strain softening corresponding to extraction of the torpedo anchor and the piezocone is similar, giving $R_{\mathrm{f}}=1$ in equation (9). As with the embedment model, deep bearing capacity factors, $N_{\mathrm{c}, \mathrm{bA}}=13.56$ and $N_{\mathrm{c}, \mathrm{bF}}=7 \cdot 5$ were adopted for the base of the anchor shaft and fins respectively. $N_{\mathrm{c}, \mathrm{tA}}=11.6$ and $N_{\mathrm{c}, \mathrm{tF}}=7.5$ were adopted at the top of the anchor shaft and fins, with due consideration given to the corresponding embedment depth relative to $D_{\mathrm{A}}$ (up to $1 \cdot 1 D_{\mathrm{A}}$ ) and $t_{\mathrm{F}}$ (up to $10 t_{\mathrm{F}}$ ), respectively ( $\mathrm{Lu}$ et al., 2004; Liyanapathirana, 2009). The strength mobilised during anchor pullout will be different to that mobilised during anchor installation owing to dynamic installation effects that cause significant effective stress changes in the soil surrounding the anchor, and strength regain following reconsolidation (Richardson et al., 2009; Hossain et al., 2014). These effects were captured by back-figuring $\alpha$ from the measured holding capacity and equation (9) using the measured (intact) shear strength profile, $s_{\mathrm{u}}=7 \cdot 5+2.9 z \mathrm{kPa}$. Fig. 11 plots these back-figured values, which fall in the narrow range $\alpha=0 \cdot 35 \sim 0 \cdot 40$, and lead to the following comments.

(a) Values of $\alpha$ for $t_{\mathrm{c}}=12.34$ months increase slightly with anchor embedment. This may be due to the entrainment of a boundary layer of water adjacent to the anchor, close to the soil surface during installation, and corresponding lower mobilised friction. For the achieved shallow embedment depths of $d_{\mathrm{e}, \mathrm{t}}=0.96$ to $1 \cdot 1 L_{\mathrm{A}}$, this effect is critical and increases with reducing $d_{\mathrm{e}, \mathrm{t}}$. For anchor

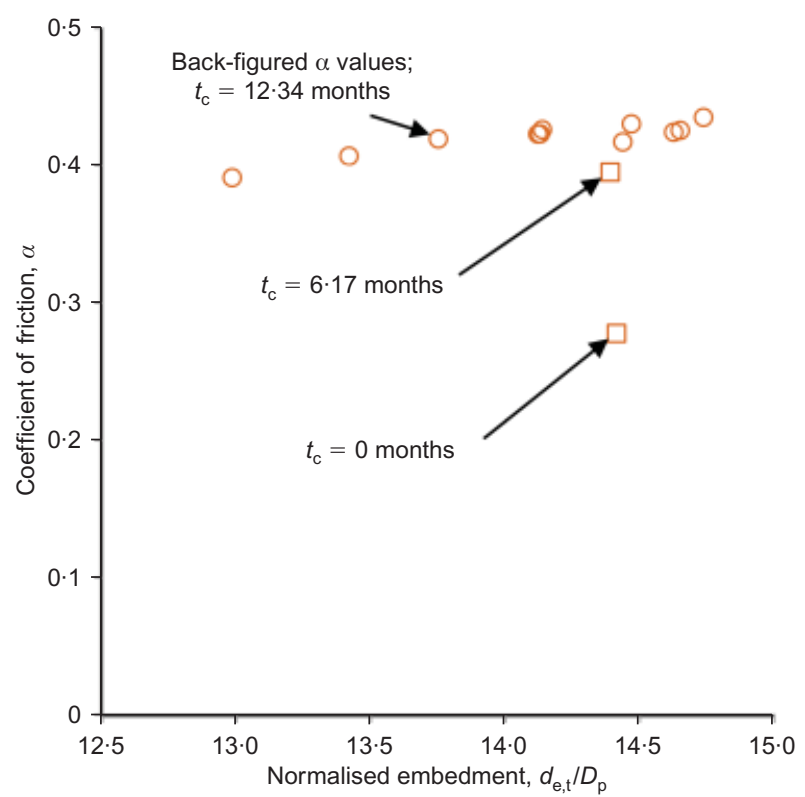

Fig. 11. Effect of embedment depth and consolidation time on coefficient of friction, $\alpha$, back-figured from measured holding capacity

installation in clay, O'Loughlin et al. (2013) also commented that water may become entrained in a boundary layer along the anchor wall during installation, which would reduce the effective normal stress at the anchor-soil interface, and consequently the friction on the anchor shaft. 
(b) The average $\alpha=0.38$ falls between $\alpha=0 \cdot 2 \sim 0.25$ (overconsolidated sample) and $\alpha=0.45$ (normally consolidated sample) reported by Randolph et al. (1998) from back-analysis of data from suction caisson pullout tests after consolidation in calcareous silt. However, it is significantly lower than $\alpha=0.65$ that would be obtained from equation (10) (below), which is commonly used for driven piles in clay (API, 2007)

$$
\alpha=0.5\left(\frac{s_{\mathrm{u}}}{\gamma^{\prime} z}\right)^{-0.5}
$$

where the bracketed term can be obtained from Fig. 3(a) and $\gamma^{\prime}=6 \cdot 1+0 \cdot 02 z \mathrm{kN} / \mathrm{m}^{3}$. For vertical pullout and $d_{\mathrm{e}, \mathrm{t}} /$ $L_{\mathrm{A}}=1 \cdot 33 \sim 1 \cdot 5$, Richardson et al. (2009) showed that $\alpha=0.25 \sim 1.75$ was required to match the holding capacity of a four-fin torpedo anchor in normally consolidated kaolin clay for varying reconsolidation periods.

(c) The average $\alpha=0.38$ corresponds to frictional capacity that is about $64 \%$ of the total holding capacity, which is lower than $75 \%$ reported by Richardson et al. (2009) for a four-fin anchor in normally consolidated kaolin clay.

(d) The trend of increasing $\alpha$ with increasing reconsolidation time is consistent with behaviour in clay as reported by Richardson et al. (2009). The lower bound $\alpha=0 \cdot 24$ corresponding to $t_{\mathrm{c}} \approx 0$ represents short-term, fully remoulded friction ratio. This value is reasonably consistent with $\alpha=1 / S_{\mathrm{t}}=0 \cdot 30 \sim 0 \cdot 36$.

Piezocone based direct design method. This is a direct design approach in which, owing to geometric similarity with the piezocone penetrometer (apart from the fins of the torpedo anchor), net tip resistance, $q_{\text {cnet }}$, and sleeve friction, $f_{\mathrm{s}}$, from a piezocone extraction test (as plotted in Fig. 12(a)) are used for calculating end bearing, $F_{\mathrm{b}}$, at the base of the anchor shaft (ignoring contribution from end bearing at the base and top of the fins and at the top of the shaft) and total frictional resistance, $F_{\mathrm{f}}$, along the shaft and fins of the anchor, respectively. This can be expressed as

$$
\begin{aligned}
F_{\mathrm{N}} & =F_{\mathrm{v}}-W_{\mathrm{ss}}=F_{\mathrm{b}}+F_{\mathrm{f}} \\
& =q_{\mathrm{cnet}} A_{\mathrm{A}}+\alpha_{\mathrm{c}}\left(f_{\mathrm{s}, \mathrm{avA}} A_{\mathrm{sA}}+f_{\mathrm{s}, \mathrm{avF}} A_{\mathrm{sF}}\right)
\end{aligned}
$$

where $F_{\mathrm{N}}$ is the net holding capacity, $\alpha_{\mathrm{c}}$ is the reduction factor for sleeve friction, and $f_{\mathrm{s}, \mathrm{avA}}$ and $f_{\mathrm{s}, \text { avF }}$ are the average sleeve friction over the embedded anchor shaft and fin length respectively. Expressed in equivalent prototype scale, the piezocone penetrometer diameter of $1.33 \mathrm{~m}$ is similar to the anchor shaft diameter of $1.07 \mathrm{~m}$ and hence $q_{\text {cnet }}$ was not averaged over a number of diameters below the piezocone tip. However, this may be necessary for field cases, where the diameter of the commonly used cone penetrometer $(35.7 \mathrm{~mm})$ is only around $4 \%$ of the typical $1 \mathrm{~m}$ shaft diameter of a torpedo anchor. Although $f_{\mathrm{s}}$ is plotted as a function of piezocone tip penetration depth, it represents the average friction over the $30 \mathrm{~mm}(\sim 4 \mathrm{~m}$ in equivalent prototype scale) length of the strain gauges above the shoulder of the piezocone. This concept, as illustrated in Fig. 12(b), is consistent with the method proposed by Nottingham (1975) and Schmertmann (1978) for assessing pile capacity in clay. Calibration of the 'immediately extracted' piezocone data (Fig. 12(a)) against measured net holding capacity for $t_{\mathrm{c}}=12.34$ months provides a range of $\alpha_{\mathrm{c}}=0.48 \sim 0.57$, increasing with increasing embedment depth (or holding capacity). This trend is consistent with that observed for $\alpha$ as discussed previously. The range of back-figured $\alpha_{\mathrm{c}}=0.48 \sim 0.57$ is within the much wider
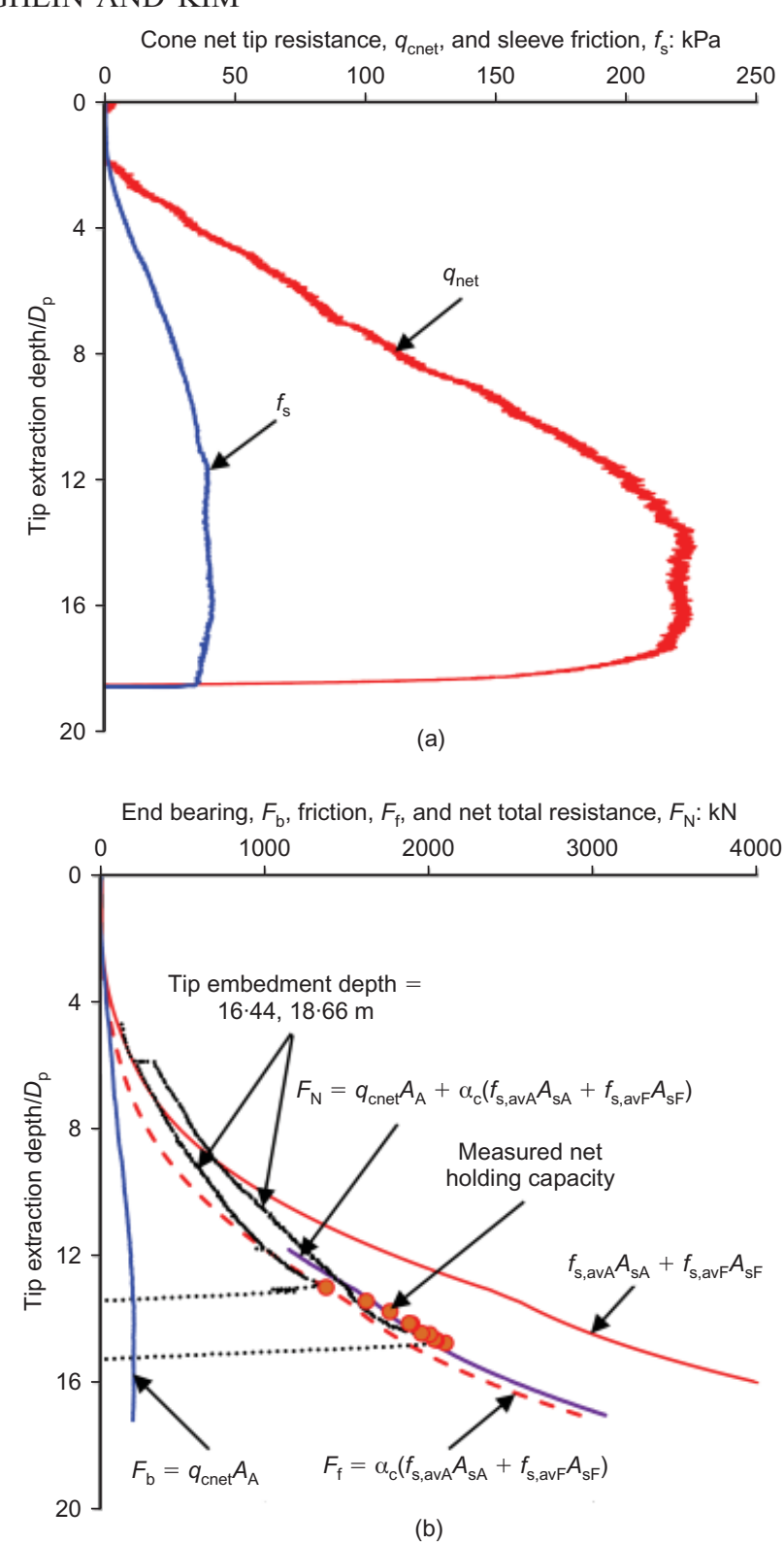

Fig. 12. Piezocone based direct design approach: (a) profiles of net tip resistance, $q_{\text {cnet }}$, and sleeve friction, $f_{\mathrm{s}}$, from piezocone penetration test; (b) comparison with measured anchor vertical extraction data

range, $\alpha_{\mathrm{c}}=0 \cdot 2 \sim 1.25$ as reported for piles in clay (Nottingham, 1975; Schmertmann, 1978). An average value of $\alpha_{\mathrm{c}}=0.55$ provides the estimate for the measured holding capacities with a maximum error of $\pm 5 \%$. For clarity, only the calculated profiles using equation (11) are included in Fig. 12(b) using this average $\alpha_{\mathrm{c}}=0 \cdot 55$. The extraction resistance profiles for tests $\mathrm{T} 1$ and $\mathrm{T} 9$ (Table 2) are also included in Fig. 12(b). Interestingly, the trend of the profiles is similar to that of average sleeve friction, confirming that total frictional resistance, $F_{\mathrm{f}}$, is the key contributor to net holding capacity. The value of $\alpha_{\mathrm{c}}$ decreases for $d_{\mathrm{e}, \mathrm{t}} / L_{\mathrm{A}} \leqslant 1$ and $t_{\mathrm{c}}=0,6 \cdot 17$ months, again consistent with the trend observed for $\alpha$.

\section{Effect of mudline load inclination, $\theta_{0}$}

In the above sections, pullout has been considered as vertical with the angle to the horizontal at the mudline, $\theta_{0}=90^{\circ}$. However, it may vary with the mooring system; for example, $\theta_{0}=0 \sim 15^{\circ}$ for catenary mooring and 
$\theta_{0}=35 \sim 55^{\circ}$ for taut leg mooring. To investigate the effect of mudline load inclination, two tests were therefore carried out at $\theta_{0}=0$ and $15^{\circ}$ (tests T14 and T15; Table 2). Test T11 with $\theta_{0}=90^{\circ}$ was taken as the corresponding base case as $t_{\mathrm{c}}$ is identical and $d_{\mathrm{e}, \mathrm{t}}$ is very similar. The extraction resistance profiles are shown in Fig. 13(a), from which it is evident that the extraction response for low values of $\theta_{0}$ is quite different to that for vertical loading (with $\theta_{0}=90^{\circ}$ ). For each considered value of $\theta_{0}$, the initial load-displacement response is similar, indicating that anchor movement is predominantly vertical. However, the holding capacity for lower values of $\theta_{0}$ is higher and is mobilised at higher anchor displacements, reflecting the increased rotation required for the anchor to be aligned with the pulling line. For vertical pullouts with $\theta_{0}=90^{\circ}$, soil disturbance was limited to a zone in the immediate vicinity of the anchor and there was negligible silt adhered to the side of the anchor after extraction from the sample (see insert in Fig. 13(a)). In contrast, for $\theta_{0}=0^{\circ}$, the anchor rotated and underwent significant displacement in the direction of the load application, disturbing a much larger zone along the anchor trajectory and with a considerable amount of silt evident on the anchor after extraction from the sample (see insert of Fig. 13(a))

The holding capacities for all tests are tabulated in Table 2. It is seen that, for vertical pullout, anchor capacity is $2 \sim 2.5$ times the dry anchor weight $\left(W_{\mathrm{d}}\right)$. For $\theta_{0}=0$ and $15^{\circ}$, this increased to $\sim 3 \cdot 3 W_{\mathrm{d}}$, which is compatible with the range and trend obtained for clayey sediments from centrifuge model tests (as discussed in the introduction to this paper).

The net holding capacity $F_{\mathrm{N}}\left(=F-W_{\mathrm{ss}}\right)$ was divided into horizontal, $F_{\mathrm{N}, \mathrm{H}}$, and vertical, $F_{\mathrm{N}, \mathrm{V}}$, components according to the loading angle, $\theta_{0}$, noting that as the anchor embedment is relatively shallow, the load angle at the anchor padeye (i.e. at the top of the shaft) is considered to be similar to that at the mudline. Fig. 13(b) shows ultimate limit states in terms of loads, indicating the size of the failure envelope in $\mathrm{H}$ (horizontal)-V (vertical) space. Hossain et al. (2014) reported data for a geometrically similar torpedo anchor tested in calcareous silt at mudline load inclinations, $\theta_{0}=45$ and $80^{\circ}$. These data are also included in Fig. 13(b), allowing better definition of the full envelope (see Figs 13(b) and 13(c)). Fig. 13(c) represents the maximum states normalised by the maximum loads, $F_{\mathrm{N}, \mathrm{v}}=F_{\mathrm{N}, \mathrm{V}} / F_{\mathrm{N}, \mathrm{V} \max }$ and $F_{\mathrm{N}, \mathrm{h}}=F_{\mathrm{N}, \mathrm{H}} / F_{\mathrm{N}, \mathrm{H} \max }$, indicating the shape and relative size of the failure envelope. de Sousa et al. (2011) reported anchor capacities for a geometrically similar torpedo anchor, as determined from small strain finite-element analyses and these data are included for comparison. However, it is worth noting that these numerical analyses did not produce clearly defined maximum capacities and the small strain limitation did not allow the rotation and large displacement response observed in Fig. 13(a) to be simulated.

Gourvenec (2008) examined the effect of the foundation embedment ratio on the $\mathrm{V}-\mathrm{H}$ failure envelope in clay. A power law was proposed to describe the shape of the normalised failure envelope for normalised embedment ratios (embedment depth relative to foundation size) $\geqslant 0.5$ as

$$
F_{\mathrm{N}, \mathrm{v}}=\left(1-F_{\mathrm{N}, \mathrm{h}}\right)^{0.25}
$$

Failure envelopes, established using results from finiteelement analyses, were proposed for short piles and hybrid pile foundations in clay (with length to diameter ratios of 2) by Fan \& Meng (2011) and El-Marassi (2011) respectively. Randolph \& House (2002) reported a failure envelope for a suction caisson (with length to diameter ratio of $\sim 1.41$ and the padeye at the top) in clay. These envelopes are also included in Fig. 13(c), where it can be seen that the best

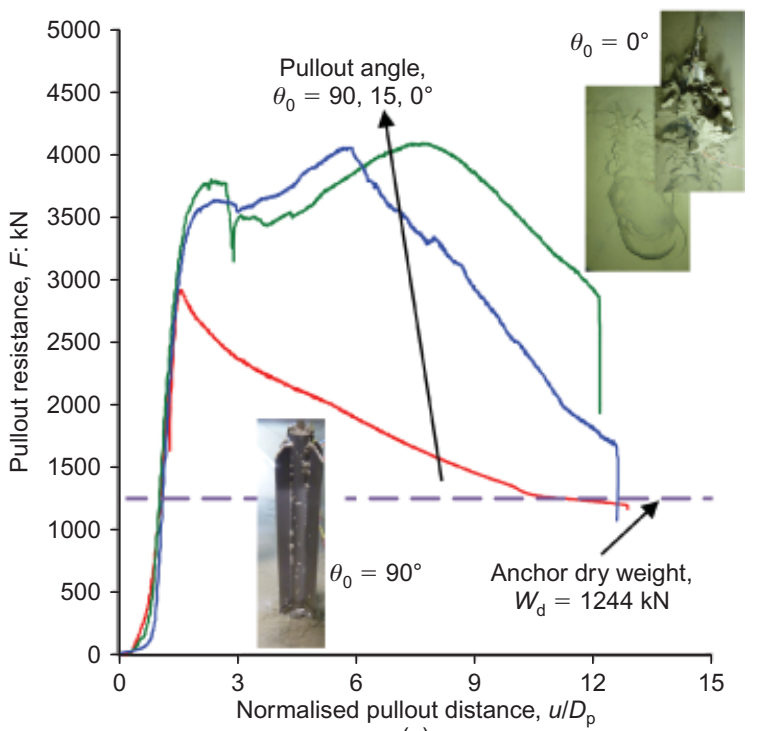

(a)

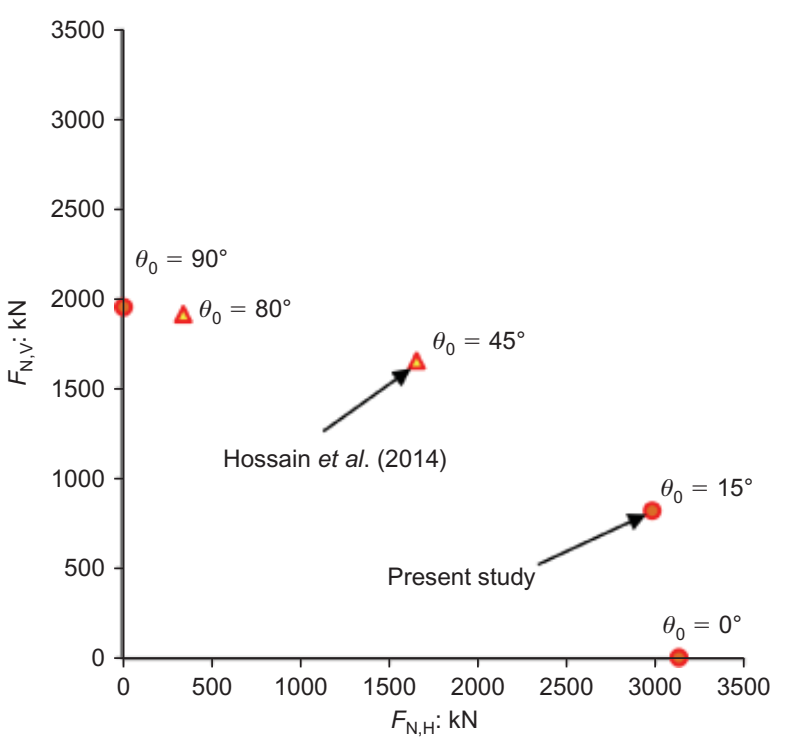

(b)

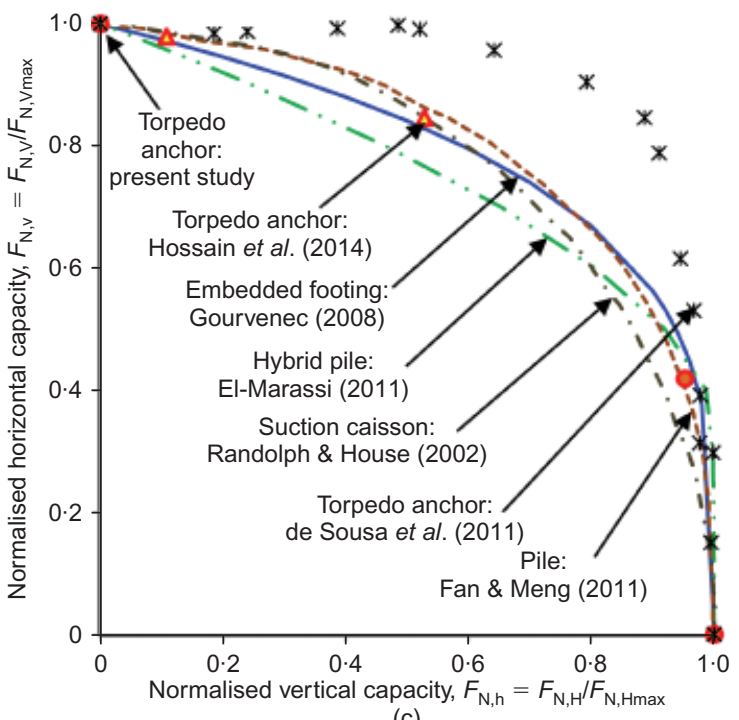

(c)

Fig. 13. Anchor capacity under inclined loading: (a) effect of pullout angle $\theta_{0}$ on extraction resistance (tests T11, T14 and T15; Table 2); (b) net holding capacity under vertical and horizontal loading; (c) failure envelope for vertical and horizontal loading in normalised load space 
agreement with the measured data is with the envelopes proposed by Fan \& Meng (2011) for piles and by Gourvenec (2008) for embedded foundations, with the latter providing the best estimate.

\section{Effect of reconsolidation time, $t_{\mathrm{c}}$, after anchor installation}

Anchor installation induces excess pore-water pressures that initially reduce the available soil strength. After installation the excess pore pressures dissipate, causing a regain in the strength of the soil surrounding the anchor. In order to examine the rate at which this strength increase occurs, three tests involving pure vertical loading with reconsolidation times $t_{\mathrm{c}}=0,6 \cdot 17$ and $12 \cdot 34$ months $\left(\theta_{0}=90^{\circ}\right.$, tests T11, T12 and T13; Table 2) are shown in Fig. 14(a). The coefficient of friction, $\alpha$, was shown previously to increase with $t_{\mathrm{c}}$ and, as expected, this increase is also reflected in an increase in the anchor holding capacity.

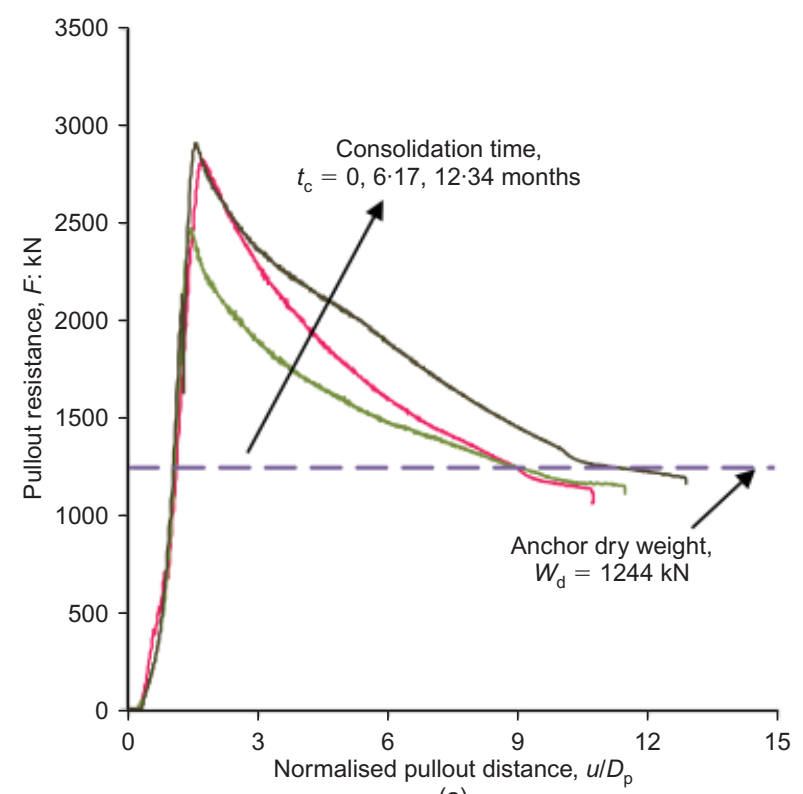

(a)

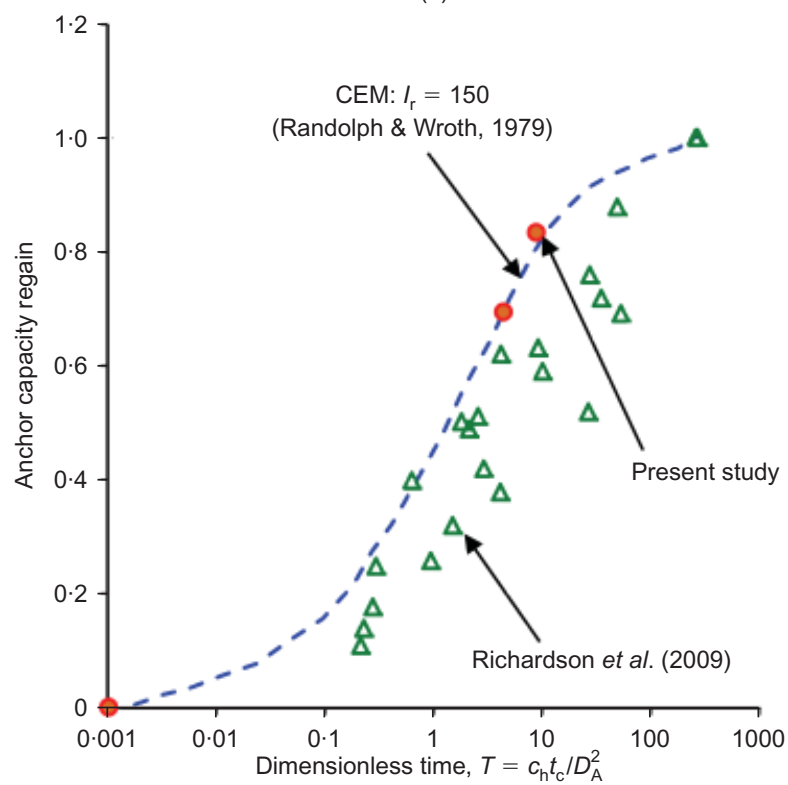

(b)

Fig. 14. Dependence of reconsolidation time after installation on anchor capacity: (a) effect of reconsolidation time $t_{\mathrm{c}}$ on extraction resistance (tests T11, T12 and T13; Table 2); (b) comparison with theoretical solutions and centrifuge model test data for clay
The rate at which reconsolidation surrounding a solid cylindrical shaft takes place can be approximated from the dissipation phase of the piezocone penetrometer test (see Fig. 3(c)), noting that the rate of consolidation is linked to $D^{2}$, and the ratio $D^{2}$ between the piezocone and the shaft of the torpedo anchor is 1.55 . It can be seen from Fig. 3(c) that around $75 \%$ and $90 \%$ consolidation took place at $t_{\mathrm{c}}=6 \cdot 17$ and 12.34 months, respectively. The $6 \cdot 17$ month reconsolidation period caused a $25 \%$ increase in anchor net holding capacity, with only an additional 5\% increase as the reconsolidation period was prolonged for a further $6 \cdot 17$ months (i.e. from $6 \cdot 17$ to $12 \cdot 34$ months).

Following the approach adopted for torpedo anchors (Richardson et al., 2009) and suction caissons (Jeanjean, 2006), the relative increase in anchor capacity was determined through consideration of the net capacity $F_{\mathrm{N}}$ relative to the immediate capacity $F_{\mathrm{N}, 0}$ and the ultimate long-term capacity $F_{\mathrm{N} \text {,max }}$, and assumed linked to the degree of consolidation by

$$
\frac{F_{\mathrm{N}}-F_{\mathrm{N}, 0}}{F_{\mathrm{N}, \max }-F_{\mathrm{N}, 0}} \approx 1-\frac{\Delta u}{\Delta u_{\max }}
$$

Figure 14(b) shows the results for tests T11, T12 and T13, plotted against dimensionless time, $T=c_{\mathrm{h}} t_{\mathrm{c}} / D_{\mathrm{A}}^{2}$, indicating the progression of anchor capacity (due to reconsolidation) with time after installation. Equivalent centrifuge model test data for torpedo anchors in kaolin clay reported by Richardson et al. (2009) are also included in Fig. 14(b); collectively the experimental data show the same trend of increasing capacity with reconsolidation time.

Theoretical solution. Richardson et al. (2009) showed that the gain in anchor capacity with reconsolidation time can be modelled using the cavity expansion method (CEM) for radial consolidation (Randolph \& Wroth, 1979) following creation of a cylindrical cavity (simulating installation of a solid, closed-ended pile). Fig. 14(b) includes the degree of consolidation predicted by the CEM for $I_{\mathrm{r}}=150$ (as derived from simple shear test data). The theoretical solution provides an accurate representation of the measured increase in capacity with time for the torpedo anchor and indicates that, for the anchor geometry and calcareous silt considered here, approximately $80 \%$ of the long-term anchor capacity would be available within 1 year of anchor installation.

\section{CONCLUDING REMARKS}

This paper has reported results from centrifuge model tests investigating dynamic installation and monotonic quasistatic pullout of a torpedo anchor in calcareous silt. For assessing anchor embedment depth for a given impact velocity (which can be calculated for field installations for a known anchor geometry, drag coefficient and drop height), a conventional shear resistance model (equation (2)) and a total energy based model (equation (8)) were shown to be capable of predicting measured embedment depths to within $\pm 3 \%$ accuracy.

Anchor holding capacity under pure vertical loading was shown to be well described using a shear resistance model based on conventional frictional and bearing resistance (equation (9)) using a coefficient of friction of 0.38. An alternative piezocone based direct design approach (equation (11)), deriving anchor end bearing and frictional resistance from piezocone tip resistance and sleeve friction, respectively, was also proposed and was seen to be capable of modelling the complete anchor extraction response using a reduction factor on sleeve friction of $\sim 0 \cdot 55$. 
Anchor holding capacity under inclined monotonic loading was presented as a combined vertical and horizontal loading failure envelope, which was well represented by a finite-element based envelope developed for embedded foundations (equation (12)).

The regain of anchor capacity due to reconsolidation of the soil surrounding the embedded anchor was shown to agree well with a cavity expansion based theoretical prediction.

\section{ACKNOWLEDGEMENTS}

The research presented herein was undertaken with support from the Australian Research Council (ARC) Discovery Early Career Researcher Award (DECRA) DE140100903 (awarded to the first author). The work forms part of the activities of the Centre for Offshore Foundation Systems (COFS), currently supported as a node of the Australian Research Council Centre of Excellence for Geotechnical Science and Engineering and as a Centre of Excellence by the Lloyd's Register Foundation. This support is gratefully acknowledged, as is the assistance of the beam centrifuge technician, Mr Manuel Palacios.

\section{NOTATION}

$A_{\mathrm{A}}$ anchor shaft cross-sectional area

$A_{\mathrm{bF}}$ anchor fins projected area

$A_{\mathrm{p}}$ projected area of anchor

$A_{\mathrm{s}}$ embedded anchor total surface area

$A_{\mathrm{SA}}$ embedded anchor shaft surface area

$A_{\mathrm{sF}}$ embedded anchor fins surface area

$c_{\mathrm{h}}$ coefficient of horizontal consolidation

$c_{\mathrm{V}}$ coefficient of vertical consolidation

$D$ diameter of any object (e.g. T-bar or piezocone)

$D_{\mathrm{A}}$ anchor shaft diameter

$D_{\mathrm{p}}$ anchor projected area equivalent diameter (including fins)

$D_{50} \quad$ average particle size of silt

$d_{\mathrm{t}}$ anchor tip penetration depth

$d_{\mathrm{e}, \mathrm{t}}$ anchor tip embedment depth

$E_{\text {total }}$ total energy

$F$ anchor pullout resistance

$F_{\mathrm{b}}$ end bearing resistance

$F_{\mathrm{b}, \mathrm{bA}}$ end bearing resistance at base of anchor shaft

$F_{\mathrm{b}, \mathrm{bF}}$ end bearing resistance at base of anchor fins

$F_{\mathrm{b}, \mathrm{tA}}$ end bearing resistance at top of anchor shaft

$F_{\mathrm{b}, \mathrm{tF}}$ end bearing resistance at top of anchor fins

$F_{\mathrm{f}}$ frictional resistance

$F_{\mathrm{fA}}$ frictional resistance along shaft

$F_{\mathrm{fF}}$ frictional resistance along fins

$F_{\mathrm{N}}$ anchor net holding capacity

$F_{\mathrm{N}, \mathrm{H}}$ horizontal component of anchor net holding capacity

$F_{\mathrm{N}, \mathrm{Hmax}}$ maximum net horizontal holding capacity

$F_{\mathrm{N}, \mathrm{h}}$ dimensionless net horizontal holding capacity $=F_{\mathrm{N}, \mathrm{H}} /$ $F_{\mathrm{N}, \mathrm{Hmax}}$

$F_{\mathrm{N}, 0} \quad$ anchor net holding capacity immediately after installation

$F_{\mathrm{N}, \max }$ anchor long-term net holding capacity

$F_{\mathrm{N}, \mathrm{V}}$ vertical component of anchor net holding capacity

$F_{\mathrm{N}, \mathrm{Vmax}}$ maximum net vertical holding capacity

$F_{\mathrm{N}, \mathrm{v}}$ dimensionless net vertical holding capacity $=F_{\mathrm{N}, \mathrm{V}} /$ $F_{\mathrm{N}, \mathrm{Vmax}}$

$F_{\mathrm{v}}$ anchor vertical holding capacity

$F_{\gamma}$ buoyant weight of soil

$f_{\mathrm{s}}$ piezocone sleeve friction

$f_{\mathrm{s}, \mathrm{avA}}$ piezocone average sleeve friction over embedded anchor shaft length

$f_{\mathrm{s} \text {,avF }}$ piezocone average sleeve friction over embedded anchor fin length

$G_{\mathrm{s}} \quad$ specific gravity

$G_{50}$ average shear modulus

$g$ Earth's gravitational acceleration

$h$ anchor drop depth $h_{\mathrm{d}}$ anchor drop height

$I_{\mathrm{r}}$ rigidity index

$k$ soil strength gradient

$L_{\mathrm{A}}$ anchor shaft length

$L_{\mathrm{F}} \quad$ anchor fin length

$L_{\mathrm{T}} \quad$ anchor shaft tip length

$m$ anchor mass

$m^{\prime}$ effective mass of anchor embedded in soil

$N_{\mathrm{c}, \mathrm{bA}}$ bearing capacity factor at base of anchor shaft

$N_{\mathrm{c}, \mathrm{bF}}$ bearing capacity factor at base of anchor fins

$N_{\mathrm{c}, \mathrm{tA}}$ bearing capacity factor at top of anchor shaft

$N_{\mathrm{c}, \mathrm{tF}}$ bearing capacity factor at top of anchor fins

$N_{\mathrm{kt}}$ bearing capacity factor of piezocone

$N_{\text {T-bar }}$ bearing capacity factor of T-bar

$q_{\text {cnet }}$ piezocone net tip resistance

$R_{\mathrm{c}}$ piezocone radius

$R_{\mathrm{f}}$ factor related to effect of strain rate and softening

$S_{\mathrm{t}}$ soil sensitivity

$s_{\mathrm{u}} \quad$ undrained shear strength

$s_{\mathrm{u}, \mathrm{SA}}$ average undrained shear strength over embedded length of anchor shaft

$s_{\mathrm{u}, \mathrm{bA}}$ undrained shear strength at base of anchor shaft

$s_{\mathrm{u}, \mathrm{bF}}$ undrained shear strength at base of anchor fins

$s_{\mathrm{u}, \mathrm{SF}}$ average undrained shear strength over embedded length of anchor fins

$s_{\mathrm{u}, \mathrm{tA}}$ undrained shear strength at top of anchor shaft

$s_{\mathrm{u}, \mathrm{tF}}$ undrained shear strength at top of anchor fins

$T$ and $T^{*}$ dimensionless time

$t_{\mathrm{c}}$ reconsolidation time

$t_{\mathrm{d}}$ dissipation time

$t_{\mathrm{F}}$ fin thickness

$U$ normalised excess pore pressure

$u$ pullout distance

$u_{2}$ pore pressure measured at shoulder of cone

$V$ dimensionless velocity

$v$ penetration and extraction velocity of any object (e.g. anchor, T-bar, piezocone)

$v_{\text {av }}$ average velocity of anchor during penetration

$v_{\text {i }}$ anchor impact velocity

$W_{\mathrm{d}}$ anchor dry weight

$W_{\mathrm{s}}$ anchor submerged weight in water

$W_{\mathrm{ss}}$ anchor submerged weight in soil

$w_{\mathrm{F}}$ anchor fin width

$z$ depth below soil surface

$\alpha$ coefficient of friction

$\alpha_{c}$ reduction factor for sleeve friction

$\beta$ shear-thinning index

$\beta_{\text {tip }}$ anchor tip angle

$\Delta u$ excess pore pressure

$\Delta u_{\max }$ maximum (i.e. at the beginning of dissipation or reconsolidation) excess pore pressure

$\dot{\gamma}$ shear strain rate

$\dot{\gamma}_{\text {ref }}$ reference shear strain rate

$\gamma^{\prime}$ effective unit weight of soil

$\eta \quad$ viscous property

$\theta_{0}$ mudline load inclination

$\lambda$ rate parameter for semi-logarithmic expression

$\mu$ rate parameter for power expression

$\rho_{\mathrm{s}} \quad$ soil density

\section{REFERENCES}

API (2007). API recommended practice $2 A$-WSD. Washington, D.C., USA: American Petroleum Institute.

Biscontin, G. \& Pestana, J. M. (2001). Influence of peripheral velocity on vane shear strength of an artificial clay. Geotech. Testing J. 24, No. 4, 423-429.

Boukpeti, N. \& White, D. J. (2011). Strength characterisation of a carbonate silt across the solid-fluid boundary report no. GEO: 11549, MERIWA project no. M395. Crawley, Western Australia: Geomechanics Group, Centre for Offshore Foundation Systems, The University of Western Australia.

Boukpeti, N., White, D. J. \& Randolph, M. F. (2012). Strength of fine-grained soils at the solid-fluid transition. Géotechnique 62, No. 3, 213-226, http://dx.doi.org/10.1680/geot.9.P.069. 
Brandão, F. E. N., Henriques, C. C. D., de Araujo, J. B., Ferreira, O. C. G. \& dos Santos Amaral, C. (2006). Albacora Leste field development - FPSO P-50 mooring system concept and installation. Proceedings of the 38th offshore technology conference, Houston, TX, paper OTC 18243.

Campanella, R. G., Robertson, P. K. \& Gillespie, D. G. (1986). Factors affecting the pore water pressure and its measurement around a penetrating cone. Proceedings of the 39th Canadian geotechnical conference, Ottawa, pp. 291-301.

Chai, J., Sheng, D., Carter, J. P. \& Zhu, H. (2012). Coefficient of consolidation from non-standard piezocone dissipation curves. Comput. Geotech. 41, 13-22.

de Araujo, J. B., Machado, R. D. \& de Medeiros Jr, C. J. (2004). High holding power torpedo pile - results for the first long term application. Proceedings of the 23rd international conference on offshore mechanics and arctic engineering, vol. 1, parts A and B, pp. 417-421. New York, NY, USA: American Society of Mechanical Engineers.

de Sousa, J. R. M., de Aguiar, C. S., Ellwanger, G. B., Porto, E. C., Foppa, D. \& de Medeiros Jr, C. J. (2011). Undrained load capacity of torpedo anchors embedded in cohesive soils. J. Offshore Mech. Arctic Engng ASME 133, No. 2, 021102.1021102.12

Einav, I. \& Randolph, M. (2005). Combining upper bound and strain path methods for evaluating penetration resistance. Int. J. Numer. Methods Engng 63, No. 14, 1991-2016.

El-Marassi, M. (2011). Investigation of hybrid monopole-footing foundation systems subjected to combined loading. $\mathrm{PhD}$ thesis, The University of Western Ontario, Canada.

Fan, Q. \& Meng, X. (2011). Failure envelope of pipe pile foundation under combined loading. In Advances in pile foundations, geosynthetics, geoinvestigations, and foundation failure analysis and repairs, ASCE Geotechnical Special Publication No. 220, pp. 109-116. Reston, VA, USA: American Society of Civil Engineers.

Finnie, I. M. \& Randolph, M. F. (1994). Bearing response of shallow foundations in uncemented calcareous soil. Proceedings of international conference centrifuge '94, Singapore, pp. 535540. Rotterdam, the Netherlands: Balkema.

Gourvenec, S. M. (2008). Effect of embedment on the undrained capacity of shallow foundations under general loading. Géotechnique 58, No. 3, 177-185, http://dx.doi.org/10.1680/geot.2008. 58.3.177.

Hossain, M. S., Kim, Y. \& Gaudin, C. (2014). Experimental investigation of installation and pull-out of dynamically penetrating anchors in clay and silt. J. Geotech. Geoenviron. Engng, ASCE 140, No. 7, 04014026-1-04014026-13.

Jeanjean, P. (2006). Set-up characteristics of suction anchors for soft Gulf of Mexico clays: Experience from field installation and retrieval. Proceedings of the 38th offshore technology conference, Houston, TX, paper OTC 18005.

Lieng, J. T., Tjelta, T. I. \& Skaugset, K. (2010). Installation of two prototype deep Penetrating anchors at the Gjoa field in the North Sea. Proceedings of the 42nd offshore technology conference, Houston, TX, paper OTC 20758.

Liyanapathirana, D. S. (2009). Arbitrary Lagrangian Eulerian based finite element analysis of cone penetration in soft clay. Comput. Geotech. 36, No. 5, 851-860.

Low, H. E., Randolph, M. F., DeJong, J. T. \& Yafrate, N. J. (2008). Variable rate full-flow penetration tests in intact and remoulded soil. Proceedings of the 3rd international conference on geotechnical and geophysical site characterization, pp. 1087-1092. Taipei, Taiwan: Taylor and Francis Group.

Low, H. E., Lunne, T., Andersen, K. H., Sjursen, M. A., Li, X. \& Randolph, M. F. (2010). Estimation of intact and remoulded undrained shear strengths from penetration tests in soft clays. Géotechnique 60, No. 11, 843-859, http://dx.doi.org/10.1680/ geot.9.P.017.

Lu, Q., Randolph, M. F., Hu, Y. \& Bugarski, I. C. (2004). A numerical study of cone penetration in clay. Géotechnique 54, No. 4, 257-267, http://dx.doi.org/10.1680/geot.2004.54.4.257.

Lunne, T. \& Andersen, K. H. (2007). Soft clay shear strength parameters for deepwater geotechnical design. Proceedings of the 6th international offshore site investigation and geotechnics conference: Confronting new challenges and sharing knowledge, vol. 1, pp. 151-176. London, UK: Society for Underwater Technology.

Mao, X. \& Fahey, M. (2003). Behaviour of calcareous soils in undrained cyclic simple shear. Géotechnique 53, No. 8, 715727, http://dx.doi.org/10.1680/geot.2003.53.8.715.

Medeiros, C. J. Jr (2002). Low cost anchor system for flexible risers in deep waters. Proceedings of the 34th offshore technology conference, Houston, TX, paper OTC 14151.

Nottingham, L. C. (1975). Use of quasi-static friction cone penetrometer data to estimate capacity of displacement piles. Gainesville, FL, USA: Department of Civil Engineering, The University of Florida.

O’Loughlin, C. D., Randolph, M. F. \& Richardson, M. D. (2004). Experimental and theoretical studies of deep penetrating anchors. Proceedings of the 36th offshore technology conference, Houston, TX, paper OTC 16841.

O’Loughlin, C. D., Richardson, M. D., Randolph, M. F. \& Gaudin, C. (2013). Penetration of dynamically installed anchors in clay. Géotechnique 63, No. 11, 909-919, http://dx.doi.org/10.1680/ geot.11.P.137.

O’Loughlin, C. D., Morton, J. P., Gaudin, C. \& White, D. J. (2014). MEMS accelerometers for measuring dynamic penetration events in geotechnical centrifuge tests. Int. J. Phys. Modelling Geotech. 14, No. 2, 31-39.

Randolph, M. F. \& House, A. R. (2002). Analysis of suction caisson capacity in clay. Proceedings of the 34th offshore technology conference, Houston, TX, paper OTC 14236.

Randolph, M. F. \& Wroth, C. P. (1979). An analytical solution for the consolidation around a driven pile. Int. J. Numer. Analyt. Methods Geomech. 3, No. 3, 217-229.

Randolph, M. F., Jewell, R. J., Stone, K. J. L. \& Brown, T. A. (1991). Establishing a new centrifuge facility. Proceedings of the international conference physical modelling in geotechnics, Centrifuge '91, Boulder, Colorado, pp. 3-9. Rotterdam, the Netherlands: Balkema.

Randolph, M. F., O’Neil, M. P., Stewart, D. P. \& Erbrich, C. (1998). Performance of suction anchors in fine-grained calcareous soils. Proceedings of the 30th offshore technology conference, Houston, TX, paper OTC 8831.

Richardson, M. D., O'Loughlin, C. D., Randolph, M. F. \& Gaudin, C. (2009). Setup following installation of dynamic anchors in normally consolidated clay. J. Geotech. Geoenviron. Engng, ASCE 135, No. 4, 487-496.

Schmertmann, J. (1978). Guidelines for cone penetration test: performance and design. Washington, D.C., USA: US Department of Transportation, Offices of Research and Development.

Teh, C. I. \& Houlsby, G. T. (1991). An analytical study of the cone penetration test in clay. Géotechnique 41, No. 1, 17-34, http:// dx.doi.org/10.1680/geot.1991.41.1.17.

True, D. G. (1974). Rapid penetration into seafloor soils. Proceedings of the 6th offshore technology conference, Houston, TX, paper OTC 2095.

White, D. J., Gaudin, C., Boylan, N. \& Zhou, H. (2010). Interpretation of T-bar penetrometer tests at shallow embedment and in very soft soils. Can. Geotech. J. 47, No. 2, 218-229.

Wilde, B. (2009). Torpedo pile anchors enter the GoM. E\&P, October, 1-2.

Zhu, H. \& Randolph, M. F. (2011). Numerical analysis of a cylinder moving through rate-dependent undrained soil. Ocean Engng 38, No. 7, 943-953.

Zimmerman, E. H., Smith, M. W. \& Shelton, J. T. (2009). Efficient gravity installed anchor for deep water mooring. Proceedings of the 41st offshore technology conference, Houston, TX, paper OTC 20117. 